\title{
๑Thermodynamic and Dynamic Responses to Deforestation in the Maritime Continent: A Modeling Study $\mathscr{A}$
}

\author{
Chu-Chun Chen And Min-Hui Lo \\ Department of Atmospheric Sciences, National Taiwan University, Taipei, Taiwan \\ EUN-SOON IM \\ Department of Civil and Environmental Engineering, Division of Environment and Sustainability, \\ Hong Kong University of Science and Technology, Hong Kong, China \\ JIN-YI YU AND YU-CHIAO LIANG \\ Department of Earth System Sciences, University of California, Irvine, Irvine, California
Wei-Ting Chen, Iping Tang, Chia-Wei lan, Ren-Jie Wu, and Rong-You Chien
Department of Atmospheric Sciences, National Taiwan University, Taipei, Taiwan

(Manuscript received 18 May 2018, in final form 13 March 2019)

\begin{abstract}
Tropical deforestation can result in substantial changes in local surface energy and water budgets, and thus in atmospheric stability. These effects may in turn yield changes in precipitation. The Maritime Continent (MC) has undergone severe deforestation during the past few decades but it has received less attention than the deforestation in the Amazon and Congo rain forests. In this study, numerical deforestation experiments are conducted with global (i.e., Community Earth System Model) and regional climate models (i.e., Regional Climate Model version 4.6) to investigate precipitation responses to MC deforestation. The results show that the deforestation in the MC region leads to increases in both surface temperature and local precipitation. Atmospheric moisture budget analysis reveals that the enhanced precipitation is associated more with the dynamic component than with the thermodynamic component of the vertical moisture advection term. Further analyses on the vertical profile of moist static energy indicate that the atmospheric instability over the deforested areas is increased as a result of anomalous moistening at approximately $800-850 \mathrm{hPa}$ and anomalous warming extending from the surface to $750 \mathrm{hPa}$. This instability favors ascending air motions, which enhance low-level moisture convergence. Moreover, the vertical motion increases associated with the MC deforestation are comparable to those generated by La Niña events. These findings offer not only mechanisms to explain the local climatic responses to MC deforestation but also insights into the possible reasons for disagreements among climate models in simulating the precipitation responses.
\end{abstract}

D Denotes content that is immediately available upon publication as open access.

Supplemental information related to this paper is available at the Journals Online website: https://doi.org/10.1175/JCLI-D18-0310.s1.

Corresponding author: Min-Hui Lo, minhuilo@ntu.edu.tw

\section{Introduction}

Anthropogenic land use and land cover changes, especially deforestation, can have substantial effects on the local and remote climate. For instance, deforestation can directly alter the partitioning of local surface energy and the water budget, leading to changes in precipitation (e.g., Zeng and Neelin 1999; Pielke et al. 2007; Mahmood et al. 2014; Lawrence and Vandecar 2015). Tropical rain forests 
have lower albedos, larger leaf and stem areas for evapotranspiration, and larger heights than other vegetation types. Therefore, converting rain forest into bare ground or grassland has three major effects on land surface conditions: 1) a reduction in evapotranspiration, 2) an increase in surface albedo, and 3) a decrease in surface roughness. The reduction in evapotranspiration decreases the surface latent heat flux and leads to a surface warming effect. The decrease in roughness reduces the aerodynamic exchanges between the surface and the atmosphere. Furthermore, the reduced roughness alone may also increase surface pressure and subsidence through land-atmosphere interactions. Although the enhanced wind speed might mitigate this effect, the net effect is a decrease in evapotranspiration (Maloney 1998). These two nonradiative processes contribute to changes in the water and energy budgets, resulting in a positive temperature response. Conversely, radiative processes reduce the net incoming radiation (through the increase in surface albedo) to produce a cooling effect. Previous studies have indicated that nonradiative processes are stronger in the tropics. As a result, warming is the net response to tropical deforestation. This differs from the temperate and boreal zones, where radiative processes are more important and the overall result of deforestation is a net cooling (Davin and de NobletDucoudré 2010; Malyshev et al. 2015).

The effects of tropical deforestation are highly dependent on the spatial scales of deforestation, the nearby environments, and the mean climates of the deforested locations (e.g., Polcher and Laval 1994; Schneck and Mosbrugger 2011; Lawrence and Vandecar 2015; Spracklen and Garcia-Carreras 2015). The climate impacts of large-scale (thousands of kilometers) tropical deforestation have been studied using numerical climate models and idealized scenarios, in which the deforestation was applied in the models throughout all tropical rain forests or within the entire Amazon or Congo basins (e.g., Sud et al. 1996; Voldoire and Royer 2004; Avissar and Werth 2005; Ramos da Silva et al. 2008; Lawrence and Vandecar 2015; Lejeune et al. 2015; Spracklen and Garcia-Carreras 2015). These large-scale deforestation experiments generally show a warmer and drier climate locally over the deforested regions. The warming effect is caused by a strong reduction in surface latent heat flux that outweighs a weaker decrease in net surface radiation, while the drying effect is caused by the reductions in transpiration, which may contribute to the simulated decreases in precipitation (e.g., Katul et al. 2012; Kumagai et al. 2013). However, there are a few large-scale deforestation studies that do not show these warmer and drier climate responses in the Congo basin and the Maritime Continent (MC) (Polcher and Laval 1994; McGuffie et al.
1995; Zhang et al. 1996a; Findell et al. 2006). The differences may result from the different vegetation types used to replace forests (e.g., grassland, scrubland, or bare ground) or broader deforestation regions (not confined to the tropics). Besides impacting local and regional climate, large-scale deforestations can also induce remote climate impacts through changes in the large-scale circulation (e.g., Hadley circulation or Walker circulation) and Rossby wave propagation in the atmosphere (e.g., Henderson-Sellers et al. 1993; Sud et al. 1996; Zhang et al. 1996b; Snyder 2010; Lawrence and Vandecar 2015).

Mesoscale deforestation (on scales of tens to hundreds of kilometers, up to $2000 \mathrm{~km}$ in scale) in areas surrounded by forest or ocean is a more realistic deforestation scenario than large-scale deforestation (e.g., Wang et al. 2009; Roy 2009; Hanif et al. 2016). Observational datasets and climate model simulations have been used to investigate the climate impact of mesoscale deforestation. Studies based on satellite observations and mesoscale climate models in southwestern Brazil have indicated that a heterogeneous land surface condition, such as a "fish-bone" deforestation pattern, can induce mesoscale atmospheric circulation under weak synoptic-scale forcing that can enhance cloudiness and rainfall (Wang et al. 2009; Negri et al. 2004; Roy 2009). A regional climate modeling study revealed an increase in precipitation at the edge of the forest in the Amazon basin due to an enhancement of prevailing wind resulting from an increased land-sea heat contrast after deforestation (Ramos da Silva et al. 2008). Observational studies have also suggested that mesoscale deforestation tends to increase local precipitation in western Malaysia; the responsible mechanisms are not clear (Hanif et al. 2016).

The Maritime Continent region has experienced dramatic forest losses in recent decades (Gaveau et al. 2014; Austin et al. 2019), but these changes have received less attention than the deforestation in the Amazon and Congo basins. Based on Landsat satellite data, the forest clearing rate in Indonesia was higher than that in the Brazilian Amazon during the period 2000-12 (Margono et al. 2014; Hansen et al. 2013). The forest area in Borneo was 55.8 Mha in 1973. By 2015 about $33.4 \%$ of it had been deforested (Gaveau et al. 2016). Deforestation has also occurred in other parts of the MC, such as Sumatra where the total forest area decreased by about $25.6 \%$ during the period $1990-2000$ (Gaveau et al. 2009). Because the MC is located within the joint ascending region of the Hadley and Walker circulations, the climate response to deforestation in this region may influence other remote regions via changes in the large-scale circulations (Mabuchi et al. 2005b; Schneck and Mosbrugger 2011). Furthermore, van der 
Molen et al. (2006) have suggested that land use and land cover changes can have greater impacts on precipitation under maritime conditions than under continental conditions due to the higher sensitivity of the sea breeze responses. It is possible that the MC deforestation can induce strong atmospheric circulation responses.

Modeling studies on the MC deforestation are consistent in finding a local warming effect of the deforestation but disagree on the precipitation response (Table 2 summarizes these modeling studies). Some of them suggested that deforestation can reduce precipitation in the MC region by weakening surface latent heat fluxes (Mabuchi et al. 2005a,b; Avissar and Werth 2005; Werth and Avissar 2005; Mabuchi 2011; Kumagai et al. 2013). However, the MC deforestation was found to intensify extreme rainfall events (i.e., the maximum daily precipitation) in a regional climate model study (Tölle et al. 2017) and enhance convection over the surrounding oceans in a fully coupled model as a weakening of upwelling causes a warming of ocean surface, leading to stronger convergence (Schneck and Mosbrugger 2011). Some of these studies also found increased precipitation under certain circumstances. For instance, Delire et al. (2001) found increased precipitation over the land regions in the $\mathrm{MC}$ using a model with prescribed sea surface temperatures. In addition, Takahashi et al. (2017) showed that, in the Weather Research and Forecasting Model, precipitation increases after decreasing the maximum stomatal conductance to one-fifth of its value in the control run, while the land cover remains the same (broadleaf evergreen). Moreover, Schneck and Mosbrugger (2011) showed that the changes in precipitation after deforestation are region-dependent. The precipitation decreases in western Borneo, northern Sumatra, and some parts in Indochina, but increases in New Guinea.

As mentioned, there is not yet a clear consensus on how precipitation responds to deforestation in the MC region. In this study, we perform MC deforestation experiments with the National Center for Atmospheric Research (NCAR) Community Earth System Model version 1.0.3 (CESM) and the Abdus Salam International Centre for Theoretical Physics (ICTP) Regional Climate Model version 4.6 (RegCM4; Giorgi et al. 2012) to uncover the mechanism that controls the precipitation response. The possible factors that may contribute to the disagreement among models in the precipitation responses are discussed.

\section{Methods}

\section{a. CESM setup for deforestation experiment}

Two simulations were performed with the CESM: the control run and the deforestation run. Both simulations were run for 30 years and the last 25 years of the simulations were used for analyses. The simulations were performed with the "F_2000_CAM5" configuration of CESM, which features the year 2000 greenhouse gas emission forcing and couples the stand-alone Community Atmosphere Model (CAM) using the CAM5 physics (Neale et al. 2012) with the Community Land Model version 4 (CLM4.0, Oleson et al. 2010; Lawrence et al. 2011). The model has a horizontal resolution of $0.9^{\circ} \times$ $1.25^{\circ}$ and is prescribed with climatological (1982-2001) sea surface temperatures and sea ice concentrations. In CLM4.0, vegetation types are represented by the plant functional types (PFTs) that describe vegetation properties such as leaf area index, stem area index, and canopy height, and thus albedo and evapotranspiration effects are varying throughout PFTs. In the deforestation experimental run, we replace the broadleaf evergreen tropical trees and broadleaf deciduous tropical trees in the $\mathrm{MC}$ region (between $10^{\circ} \mathrm{S}-10^{\circ} \mathrm{N}$ and $90^{\circ}-150^{\circ} \mathrm{E}$ ) by $\mathrm{C} 4$ grasses. Figure $\mathrm{S} 1$ in the online supplemental material shows the changes in the spatial distributions of PFT. We replace trees with $\mathrm{C} 4$ grass as a proxy for oil palm, which is one of the major vegetation types occupying the $\mathrm{MC}$ after deforestation (Carlson et al. 2012). Some of the characteristics of $\mathrm{C} 4$ grass and oil palm are similar. For example, the respiration rate of oil palm in the rainy season is $38-75 \mathrm{mg} \mathrm{H}_{2} \mathrm{O} \mathrm{m}^{-2} \mathrm{~s}^{-1}$ (Radersma and de Ridder 1996), and the respiration rate for one species of $\mathrm{C} 4$ grass is $75.8809 \mathrm{mg} \mathrm{H}_{2} \mathrm{O} \mathrm{m}^{-2} \mathrm{~s}^{-1}$ (Snyman et al. 1997). In addition, if the forest was not converted into oil palm, C4 grass would still be the most probable vegetation type growing in the tropics (Sage et al. 1999).

\section{b. RegCM4 setup for deforestation experiment}

To further confirm the deforestation response revealed by the coarse-resolution CESM, we also performed the control and deforestation experiments with the Regional Climate Model version 4.6 (hereafter referred to simply as RegCM4; Giorgi et al. 2012). The domain covers the whole $\mathrm{MC}$ region including the regions where land use type for CESM run was converted from the broadleaf evergreen tropical trees and broadleaf deciduous tropical trees to warm $\mathrm{C} 4$ grasses. The horizontal resolution is $50 \mathrm{~km}$ with 60 (north-south direction: $12.0018^{\circ} \mathrm{S}-$ $\left.12.9781^{\circ} \mathrm{N}\right) \times 160$ (east-west direction: $89.9264^{\circ}-$ $160.074^{\circ} \mathrm{E}$ ) grid points (see Fig. 1 for the RegCM4 domain used in this study), while 23 vertical levels are used within the sigma coordinate. A buffer zone of eight grid points is assigned to each lateral boundary. For the basic configuration of RegCM4, we use the radiative transfer scheme of the modified NCAR Community Climate Model version 3 (CCM3), the nonlocal planetary boundary layer scheme of Holtslag (Holtslag et al. 1990), 


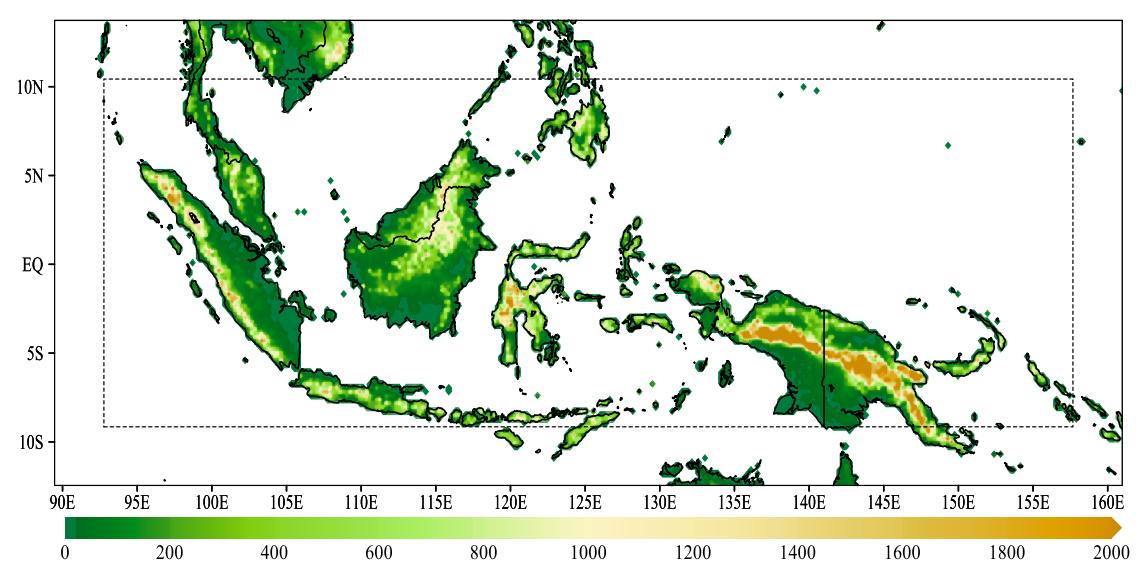

FIG. 1. The geographic domain for the RegCM4 model simulations. The dashed line is the buffer zone of eight grid points assigned to each lateral boundary.

the ocean flux scheme of Zeng (Zeng et al. 1998), and the Subgrid Explicit Moisture (SUBEX) scheme for the resolved scale precipitation, which are default schemes of RegCM4 (Giorgi et al. 2012) or applied schemes for RegCM4 simulations of the Southeast Asia domain (Chung et al. 2018). We also performed sensitivity experiments with various cumulus schemes to decide that using the cumulus scheme of Emanuel (1991) for land grids and the cumulus scheme of Tiedtke (1996) for ocean grids produces the best model performance. As for the land surface scheme, CLM4.5 newly incorporated within RegCM4 is used. Therefore, the land use distributions used for RegCM4 control and deforestation experiments are exactly the same as those from CESM (in terms of the RegCM4 domain) except for the discrepancy caused by the different resolution. The initial and lateral boundary conditions are obtained from the European Centre for Medium-Range Weather Forecasts (ECMWF) interim reanalysis (ERAInterim) with a resolution of $1.5^{\circ} \times 1.5^{\circ}$ at 6 -h intervals. The sea surface temperatures (SSTs) are prescribed by ERAInterim with a resolution of $1.5^{\circ} \times 1.5^{\circ}$ at 6 -h intervals. Both simulations (deforestation and control experiments) span 23 years from January 1979 to December 2001. The first 3 years were used as the spinup period and were excluded in the analyses. This spinup time is considered long compared to many other studies that used regional climate models to investigate impact of land-use change (e.g., Laux et al. 2017; Zhang et al. 2016; Wang and Cheung 2017). The resulting 20-yr simulations cover the period of 1982-2001, which is the period used to define the climatological SST prescribed in the CESM experiments.

\section{c. Observational data: Precipitation, near-surface air temperature, and outgoing longwave radiation}

We used four observation-based precipitation datasets to evaluate the land precipitation over the $\mathrm{MC}$ region in the simulations: the Global Precipitation Climatology Centre (GPCC) dataset (Schneider et al. 2011) with a horizontal resolution of $0.5^{\circ} \times 0.5^{\circ}$; the National Oceanic and Atmospheric Administration's Precipitation Reconstruction over Land (PREC/L) (Chen et al. 2002) with a horizontal resolution of $0.5^{\circ} \times 0.5^{\circ}$; the Asian Precipitation-Highly Resolved Observational Data Integration Toward Evaluation of the Water Resources (APHRODITE; Yatagai et al. 2012) with a horizontal resolution of $0.25^{\circ} \times 0.25^{\circ}$; and the GPCP One-Degree Daily (1dd) data (Huffman et al. 2001) with a horizontal resolution of $1^{\circ} \times 1^{\circ}$. All datasets were constructed from gauge-based precipitation, and GPCP has also incorporated the information from the satellite data. We used two observational near-surface air temperature (SAT) global land gridded products from CRU TS v. 4.01 (Harris et al. 2014) and from the University of Delaware (UoD) surface air temperature dataset (Willmott and Matsuura 2001). The gridded monthly NOAA interpolated outgoing longwave radiation (OLR) from NCAR with temporal interpolation (Liebmann and Smith 1996) was also used in this study.

\section{d. Surface energy balance equation}

We analyze the surface energy balance following Eq. (1) of Chen and Dirmeyer (2016):

$$
R_{\mathrm{net}}=S_{\mathrm{net}}+\mathrm{LW}_{\mathrm{in}}-\varepsilon \sigma T_{s}^{4}=H+\mathrm{LE}+G,
$$

where $R_{\text {net }}$ is the net radiation at the surface, $S_{\text {net }}$ is the net shortwave flux at the surface, $\mathrm{LW}_{\text {in }}$ is the downward longwave flux at the surface, and $\varepsilon \sigma T_{s}^{4}$ is the upward longwave flux at the surface based on the StefanBoltzmann law (the value of emissivity $\varepsilon$ depends on surface cover type). For $R_{\text {net }}, S_{\text {net }}$, and $\mathrm{LW}_{\text {in }}$, the downward direction is positive. The net radiation at the surface 
is also equal to the net surface heat flux, where $H$ is surface sensible heat flux, LE is surface latent heat flux, and $G$ is ground heat flux. For $H$ and LE, the upward direction is positive, and for $G$ the downward direction is positive.

\section{e. Moisture budget equation}

To understand the mechanism that determines the precipitation response to the $\mathrm{MC}$ deforestation, we diagnosed the moisture budget using the following vertically integrated moisture budget equation:

$$
\left\langle\frac{\partial q}{\partial t}\right\rangle=\mathrm{ET}-P-\langle\nabla \cdot(\mathbf{v} q)\rangle
$$

where $q$ is the specific humidity, ET is evapotranspiration, $P$ is precipitation, and $\mathbf{v}$ is the three-dimensional velocity. Angle brackets $(\langle\rangle)$ denote mass integration through the troposphere:

$$
\langle X\rangle=\frac{1}{g} \int_{p_{s}}^{p_{t}} X d p,
$$

where $g$ is the gravitational acceleration, $p_{t}$ is the pressure at the tropopause (set to $100 \mathrm{hPa}$ in this study), and $p_{s}$ is surface pressure. Since the vertical velocity $\omega$ is near zero at the surface and tropopause (Tan et al. 2008), the divergence of moisture flux can be estimated as

$$
\langle\nabla \cdot(\mathbf{v} q)\rangle \approx\langle\mathbf{v} \cdot \nabla q\rangle+\left\langle\omega \frac{\partial q}{\partial p}\right\rangle,
$$

where $\langle\mathbf{v} \cdot \nabla q\rangle$ is the vertically integrated horizontal moisture advection and $\langle\omega(\partial q / \partial p)\rangle$ is the vertically integrated vertical moisture advection. Since the longterm averaged $\langle\partial q / \partial t\rangle$ is negligible, the anomalies of vertically integrated moisture budget equation can be written as (Chou and Neelin 2004; Chou et al. 2006)

$$
P^{\prime} \approx \mathrm{ET}^{\prime}-\langle\mathbf{v} \cdot \nabla q\rangle^{\prime}-\left\langle\omega \frac{\partial q}{\partial p}\right\rangle^{\prime}
$$

where the prime $\left({ }^{\prime}\right)$ represents the differences between control simulation and deforestation experimental simulation. The changes in vertically integrated vertical moisture advection can be further divided into two components:

$$
-\left\langle\omega \frac{\partial q}{\partial p}\right\rangle^{\prime} \approx-\left\langle\bar{\omega} \frac{\partial q^{\prime}}{\partial p}\right\rangle-\left\langle\omega^{\prime} \frac{\partial \bar{q}}{\partial p}\right\rangle
$$

where $\left(^{-}\right)$denotes the value from the control simulation and ()$^{\prime}$ denotes the difference between control simulation and deforestation experimental simulation. The first term $-\left\langle\bar{\omega}\left(\partial q^{\prime} / \partial p\right)\right\rangle$ is referred to as the thermodynamic component, which is associated with changes in water vapor. The second term $-\left\langle\omega^{\prime}(\partial \bar{q} / \partial p)\right\rangle$ is the dynamic component, which is associated with changes in convection. Notice that we use $\mathrm{Wm}^{-2}$ as the unit for the terms in the water budget equations, including precipitation, which, divided by 28 , is $\mathrm{mm} \mathrm{day}^{-1}$.

\section{f. Moist static energy}

To understand mechanisms that induce changes in convection, we analyzed the vertical profile of moist static energy (MSE) anomalies. The MSE is the sum of sensible, latent, and potential energy and is defined as

$$
\mathrm{MSE}=C_{P} T+L q+g z,
$$

where $C_{P}$ is the specific heat of air at constant pressure, $T$ is the temperature, $L$ is the latent heat of vaporization, $q$ is the specific humidity, $g$ is the acceleration of gravity, and $z$ is height.

\section{Results}

\section{a. Validations of precipitation, near-surface air temperature, and $O L R$}

Figures $2 \mathrm{a}-\mathrm{c}$ show the annual mean precipitation from a 25-yr CESM control simulation, a 20-yr (1982-2001) RegCM4 control simulation, and four observational datasets (GPCC: 1982-2001; PREC/L: 1982-2001; GPCP: 1997-2012; APHRODITE: 1982-2001). The pattern correlation coefficients $(r)$ and root-mean-square errors (RMSEs) are also displayed in the title of each panel; note that the $r$ and RMSE are calculated at the CESM model spatial resolution $\left(0.9^{\circ} \times 1.25^{\circ}\right)$. The seasonal comparisons are provided in the supplemental material (Fig. S2A for both CESM and RegCM4). Figures 2a-c show that the simulated land precipitation over the MC region is reasonably close to the observations, although the values are overestimated over New Guinea in both CESM and RegCM4. CESM underestimates the precipitation over central Borneo, whereas RegCM4 does capture the local maximum values over central Borneo.

However, the pattern correlation coefficient between the precipitation in the observation ensemble and in RegCM4 is actually lower (0.14) than that between the observation ensemble and CESM (0.39). The RMSE of precipitation in RegCM4 is also higher when compared to the results in the CESM (12.27 $\mathrm{mm} \mathrm{day}^{-1}$ for RegCM4 and $3.15 \mathrm{~mm} \mathrm{day}^{-1}$ for CESM). This may be partly due to the high spatial variation in the RegCM4 simulations and the dry biases exhibited by 

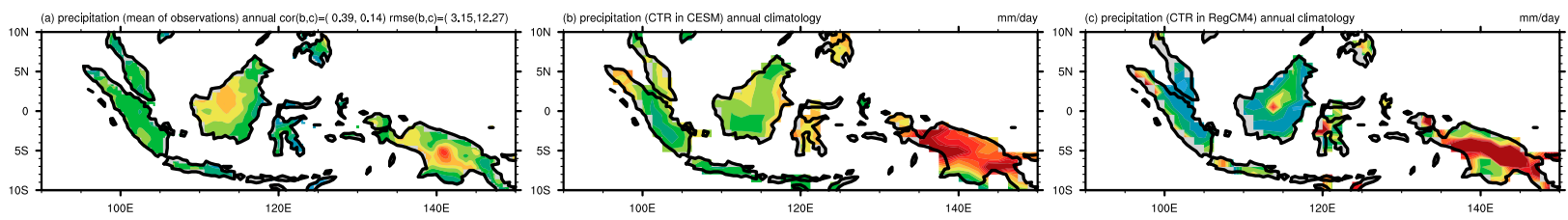

100E

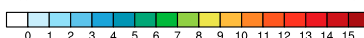

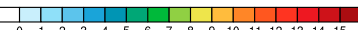
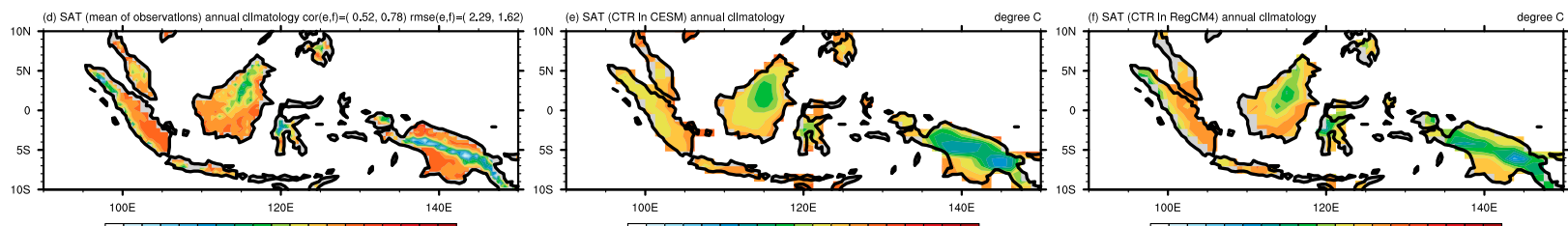

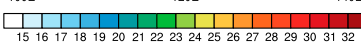

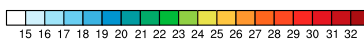
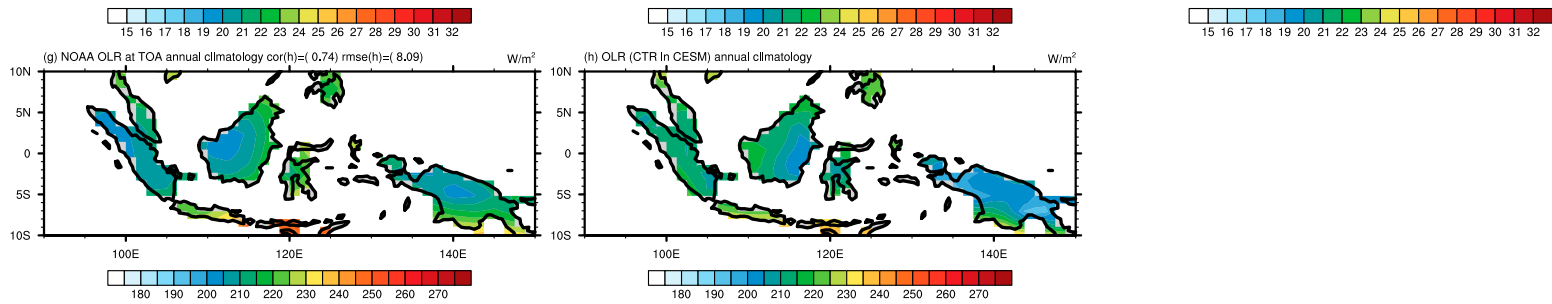

FIG. 2. Annual mean precipitation ( $\mathrm{mm} \mathrm{day}^{-1}$ ) from (a) the average of four observed precipitation datasets, (b) the CESM control run (25-yr average), and (c) RegCM4 (20-yr average). Also shown are annual mean near-surface temperature $\left({ }^{\circ} \mathrm{C}\right)$ from (d) the average of two observed datasets, (e) CESM control run (25-yr average), and (f) RegCM4 (20-yr average), and annual mean top of atmosphere outgoing longwave radiation $\left(\mathrm{W} \mathrm{m}^{-2}\right)$ from $(\mathrm{g})$ the observation and $(\mathrm{h})$ the CESM control run (25-yr average).

the model in the coastal regions of Borneo and eastern Sumatra. We also examine the spatial patterns of the four observational datasets for the annual and seasonal means (Fig. S2B). In general, GPCC, GPCP, and PREC/L show similar spatial patterns (see Table S1; for annual means, $r$ between GPCC and GPCP is 0.68; $r$ between GPCC and PREC/L is 0.8 ; $r$ between GPCP and $\mathrm{PREC} / \mathrm{L}$ is 0.74$)$. APHRODITE shows different spatial patterns from the others due to its higher spatial resolution $\left(0.25^{\circ} \times 0.25^{\circ}\right)$, which leads to higher spatial maxima in precipitation. GPCP has a relatively lower spatial resolution $\left(1^{\circ} \times 1^{\circ}\right)$; thus, its pattern correlation coefficients with the other three datasets are usually low (see Table S1; for the annual means, $r$ between GPCP and GPCC is 0.68 ; $r$ between GPCP and PREC/L is 0.74 ; $r$ between GPCP and APHRODITE is 0.55).

The near-surface air temperatures are reasonably well simulated in both models. In particular, the RegCM4 can capture a number of topographic effects very clearly in central Borneo and New Guinea (Figs. 2d-f). Therefore, the simulated SAT in RegCM4 has a relatively higher pattern correlation coefficient and lower $\operatorname{RMSE}\left(0.78^{\circ}\right.$ and $\left.1.6^{\circ} \mathrm{C}\right)$ than those in $\operatorname{CESM}\left(0.52^{\circ}\right.$ and $2.2^{\circ} \mathrm{C}$ ). In comparison to the observed OLR, the CESM not only captures the spatial pattern with high pattern correlation coefficients $(0.74)$ but also produces a similar magnitude (Figs. 2g,h). Note that the OLR is not available from the RegCM4 model at present so only the CESM result is shown. The seasonal simulations
(Figs. S2c,d) have biases that are similar to those in the annual-mean simulations despite having different magnitudes and spatial patterns.

\section{b. Local hydroclimate response to MC deforestation}

To examine the local climate responses to the MC deforestation, we compared the deforestation run to the control run in CESM as well in RegCM4 on an annual mean basis. The local climate responses during different seasons usually have the same signs as that in the annual mean response (except for the precipitable water in SON and DJF, cloud cover in CESM, and the net surface longwave radiation and sensible heat fluxes in RegCM4) despite having different magnitudes and spatial patterns. Therefore, we only show and discuss the annual mean changes in Fig. 3 (from the CESM experiments) and Fig. 4 (from the RegCM4 experiments) and Table 1. The seasonal changes are provided in the supplemental material (Figs. S3a-j and Tables S2 and S3).

The land surface temperatures in the deforestation run are warmer than the control run by about $1 \mathrm{~K}$ (with $p$ value $<0.05$ ) when averaged over the entire MC land in the CESM simulations (Fig. 3a). To understand the temperature response to deforestation, we analyzed the changes in surface radiation and surface heat flux in Eq. (1). For the nonradiative fluxes, we find an increase in the surface sensible heat flux (Fig. 3b) and a significant decrease in the surface latent heat flux (Fig. 3c) over the deforested area of the MC in the deforestation 

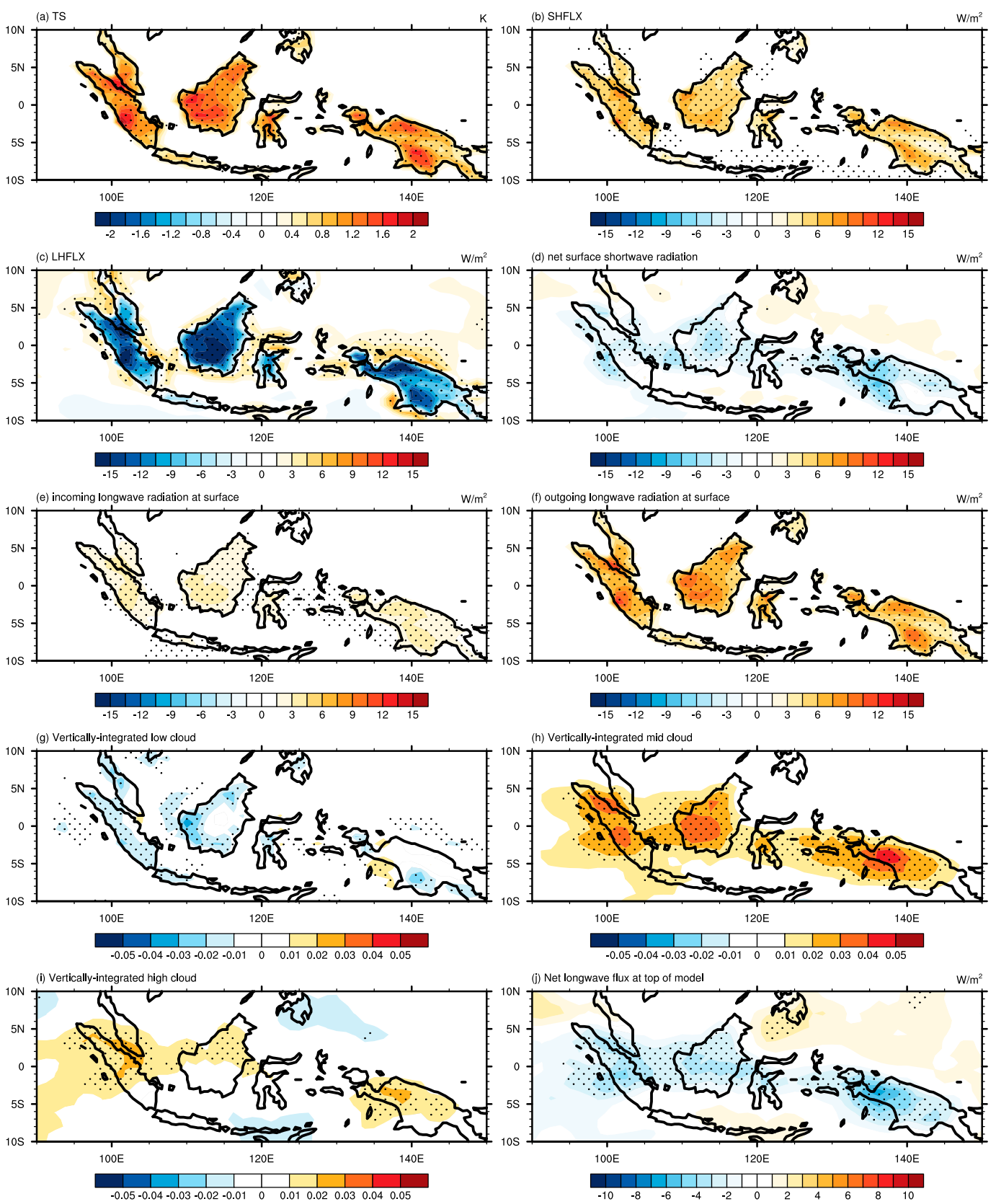

FIG. 3. Difference between deforestation experimental run and control run (DEF minus CTR) in annual mean (a) surface temperature $(\mathrm{K})$, (b) surface sensible heat flux $\left(\mathrm{W} \mathrm{m}^{-2}\right)$, (c) surface latent heat flux $\left(\mathrm{W} \mathrm{m}^{-2}\right)$, (d) net shortwave flux at surface $\left(\mathrm{W} \mathrm{m}^{-2}\right)$, (e) incoming longwave flux at surface $\left(\mathrm{W} \mathrm{m}^{-2}\right)$, (f) outgoing longwave flux at surface $\left(\mathrm{W} \mathrm{m}^{-2}\right)$, (g) vertically integrated low cloud cover, (h) vertically integrated midcloud cover, (i) vertically integrated high cloud cover, and (j) top of atmosphere outgoing longwave flux $\left(\mathrm{W} \mathrm{m}^{-2}\right)$. Dotted areas indicate $p<0.05$.

run. It is clear from Figs. $3 b$ and $3 c$ that the decrease in the latent heat flux $\left(-9.60 \mathrm{~W} \mathrm{~m}^{-2}\right.$, with $p$ value $<$ $0.05)$ is larger than the increase in the sensible heat flux $\left(5.08 \mathrm{~W} \mathrm{~m}^{-2}\right.$, with $p$ value $\left.<0.05\right)$ in terms of absolute changes. Deforestation leads to lower evapotranspiration and reduced roughness, which weaken the aerodynamic exchanges. These two effects result in a larger magnitude of latent heat flux reduction, and the latter can also reduce the magnitude of the sensible heat flux increase. Note that the increase in surface latent heat flux in coastal regions is due to the larger near-surface wind speeds (induced by the 

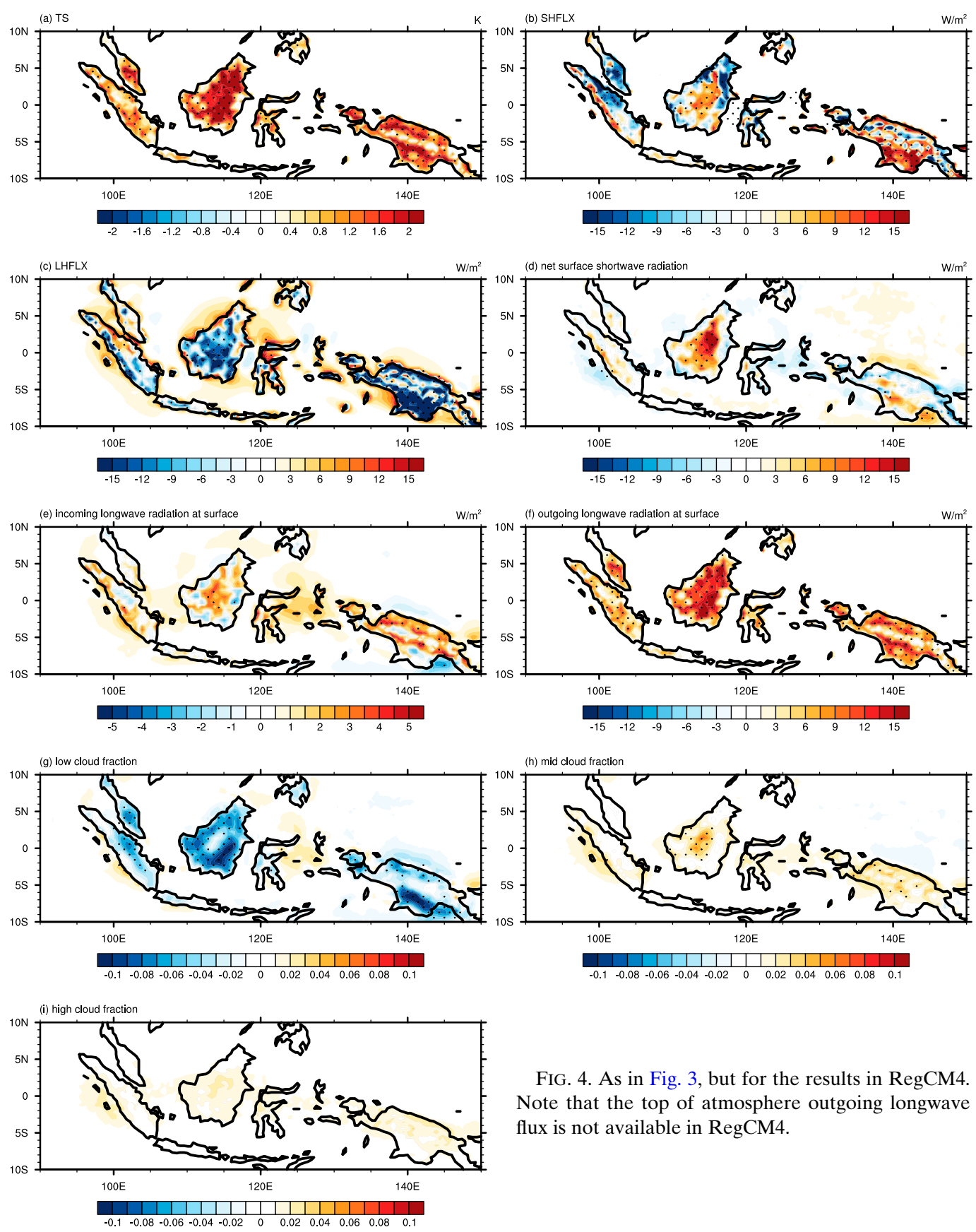

FIG. 4. As in Fig. 3, but for the results in RegCM4. Note that the top of atmosphere outgoing longwave flux is not available in RegCM4.

warmer land surface and reduced roughness) there after deforestation.

Furthermore, there are increases in midlevel $(2.02 \%$, with $p$ value $<0.05)$ and high-level $(0.86 \%$, with $p$ value $<0.05)$ cloud cover but decreases in low level cloud cover $(-1.02 \%$, with $p$ value $<0.05)$ as revealed by the vertical changes in cloud cover over the MC land regions (Figs. 3g-i and Table 1). The decrease in low cloud cover is consistent with the more stable environment in the low atmosphere due to decreases in near-surface water vapor after deforestation. The decreased low clouds also correspond to more incoming downward solar radiation but also less downward longwave radiation at the surface. The increased mid- and high-level clouds are associated with less incoming downward solar radiation but more downward longwave radiation. Therefore, the changes in net cloud forcing at the land surface are minimal.

Regarding the surface radiation budget, the increase in surface albedo $(1.38 \%$, with $p$ value $<0.05)$ from the 
TABLE 1. Effects of Maritime Continent deforestation in the CESM and RegCM4 at annual basis (DEF minus CTR) with boldface values indicating statistically significant differences at $p<$ 0.05 . Percentage changes are also shown below each anomaly.

\begin{tabular}{|c|c|c|c|}
\hline Variable & Units & ANN-CESM & ANN-RegCM4 \\
\hline \multirow{2}{*}{$\begin{array}{l}\text { Net surface shortwave } \\
\text { radiation flux }\end{array}$} & $\mathrm{W} \mathrm{m}^{-2}$ & -1.88 & 5.56 \\
\hline & $\%$ & -1.36 & 13.57 \\
\hline \multirow{2}{*}{$\begin{array}{l}\text { Net surface longwave } \\
\text { radiation flux }\end{array}$} & $\mathrm{W} \mathrm{m}^{-2}$ & 3.81 & 0.07 \\
\hline & $\%$ & 13.91 & 0.03 \\
\hline \multirow{2}{*}{$\begin{array}{l}\text { Surface sensible heat } \\
\quad \text { flux }(H)\end{array}$} & $\mathrm{W} \mathrm{m}^{-2}$ & 5.08 & 0.17 \\
\hline & $\%$ & 41.50 & 0.67 \\
\hline \multirow{2}{*}{$\begin{array}{l}\text { Surface latent heat } \\
\text { flux (LE) }\end{array}$} & $\mathrm{W} \mathrm{m}^{-2}$ & -9.60 & -7.28 \\
\hline & $\%$ & -9.99 & -5.62 \\
\hline \multirow{2}{*}{$\begin{array}{l}\text { Surface temperature } \\
\quad\left(T_{\mathrm{s}}\right)\end{array}$} & ${ }^{\circ} \mathrm{C}$ & 1.04 & 1.07 \\
\hline & $\%$ & 0.35 & 0.36 \\
\hline \multirow[t]{4}{*}{ Precipitation } & $\mathrm{mm} \mathrm{day}^{-1}$ & 0.59 & 1.30 \\
\hline & $\%$ & 6.64 & 13.74 \\
\hline & $\mathrm{W} \mathrm{m}^{-2}$ & 16.5 & 36.4 \\
\hline & $\%$ & 6.64 & 13.74 \\
\hline \multirow[t]{2}{*}{ Precipitable water } & $\mathrm{kg} \mathrm{m}^{-2}$ & 0.23 & 0.19 \\
\hline & $\%$ & 0.49 & 0.42 \\
\hline \multirow{2}{*}{$\begin{array}{l}\text { Outgoing longwave } \\
\text { radiation (OLR) }\end{array}$} & $\mathrm{W} \mathrm{m}^{-2}$ & -2.06 & -0.34 \\
\hline & $\%$ & -0.97 & $-\mathbf{0 . 1 3}$ \\
\hline \multirow[t]{2}{*}{ High-level cloud cover } & & 0.86 & 1.09 \\
\hline & $\%$ & 1.22 & 2.34 \\
\hline \multirow[t]{2}{*}{ Midlevel cloud cover } & & 2.02 & 1.40 \\
\hline & $\%$ & 4.46 & 7.62 \\
\hline \multirow[t]{2}{*}{ Low cloud cover } & & -1.02 & -3.79 \\
\hline & $\%$ & -2.13 & -7.34 \\
\hline \multirow[t]{2}{*}{ Total cloud cover } & & 0.38 & -0.78 \\
\hline & $\%$ & 0.45 & -1.54 \\
\hline \multirow{2}{*}{$\begin{array}{l}\text { Upward longwave flux } \\
\text { at the surface }\end{array}$} & $\mathrm{W} \mathrm{m}^{-2}$ & 6.32 & 5.31 \\
\hline & $\%$ & 1.41 & 12.72 \\
\hline \multirow[t]{2}{*}{ Surface albedo } & & 1.38 & 5.52 \\
\hline & $\%$ & 11.63 & 48.90 \\
\hline
\end{tabular}

deforestation and the increase in total cloud cover $(0.38 \%$, with $p$ value $<0.05)$ would together reduce the net shortwave radiation at the surface (Fig. 3d; $-1.88 \mathrm{~W} \mathrm{~m}^{-2}$, with $p$ value $\left.<0.05\right)$. As for the surface longwave radiative flux, we find an increase in the net longwave (Fig. 3e; $3.81 \mathrm{~W} \mathrm{~m}^{-2}$, with $p$ value $<0.05$ ). The enhanced net longwave may be a result of the increases in surface temperature. To compensate for the reduced surface flux, which was mainly due to a decrease in the latent heat flux, the upward longwave flux at the surface must increase (Fig. 3f; $6.32 \mathrm{~W} \mathrm{~m}^{-2}$, with $p$ value $<0.05$ ), accompanied by a rise in surface temperature according to the Stefan-Boltzmann law (Fig. 3a). Our results on these local near-surface responses are consistent with previous studies suggesting that the nonradiative processes usually have a stronger influence than radiative processes in determining the deforestation impacts on surface temperature in the tropics (Davin and de Noblet-Ducoudré 2010; Malyshev et al. 2015).
The responses in the RegCM4 are in general similar to those in the CESM (except the net shortwave radiation), but with a higher spatial heterogeneity (Fig. 4), which is expected because of the higher spatial resolution of the regional model. For example, changes in surface temperature are similar to those in the CESM, with an increase of approximately $1 \mathrm{~K}$ on average for the $\mathrm{MC}$ land region, but the magnitude of the changes in the RegCM4 is larger in some regions (central Borneo and New Guinea coastal regions). A similar tendency can be found in the responses of outgoing longwave radiation at the surface (Figs. $3 \mathrm{f}$ and $4 \mathrm{f}$ and Table 1 ). The sensible heat flux response in the RegCM4 is heterogeneous (Fig. 4b) and does not always increase as in the CESM. For example, the RegCM4 deforestation experiments show significant decreases in northern Borneo and eastern Sumatra. The sensible heat flux response averaged over the entire MC land regions is close to zero in the RegCM4. The responses in latent heat fluxes of the RegCM4 and CESM simulations are mostly similar (significant decreases after deforestation, $-7.28 \mathrm{~W} \mathrm{~m}^{-2}$, with $p$ value $<0.05$ ), but there are increased latent heat fluxes in northern Sumatra and parts of northern Borneo in the RegCM4.

Moreover, the decrease in low cloud cover in the RegCM4 simulations is much larger $(-3.79 \%$, with $p$ value $<0.05)$ than that in CESM so the total cloud cover also decreases in the RegCM4 $(-0.78 \%$, with $p$ value $<0.05)$. The total cloud cover changes are different in the CESM and RegCM4. However, the tendency of changes in the vertical structure (increase in middle to high cloud and decrease in low clouds) is the same in CESM and RegCM4 (Figs. 3 and 4 and Table 1). Because of the decrease in total cloud cover in the RegCM4, the net surface shortwave radiation flux increases significantly $\left(5.56 \mathrm{~W} \mathrm{~m}^{-2}\right.$, with $p$ value $\left.<0.05\right)$, which is opposite to the results obtained with CESM.

\section{c. Precipitation response to $M C$ deforestation in CESM}

We next examine the precipitation response to the MC deforestation by calculating the precipitation changes between the control run and the deforestation run (Fig. 5a) in the CESM. The figure shows that simulated precipitation increases over the land and coastal areas of the MC. Over the deforested areas, the precipitation increased by about $16.5 \mathrm{~W} \mathrm{~m}^{-2}$ (i.e., $0.59 \mathrm{~mm} \mathrm{day}^{-1}$, with $p$ value $<0.05$ ), which was $6.6 \%$ of the mean precipitation in the control run. Our result differs from those of some previous studies that find precipitation decreases in response to deforestation in the MC (Avissar and Werth 2005; Mabuchi et al. 2005a,b; Werth and Avissar 2005; Mabuchi 2011; Kumagai et al. 2013). 


\section{CESM Climatology Difference (DEF-CTR)}

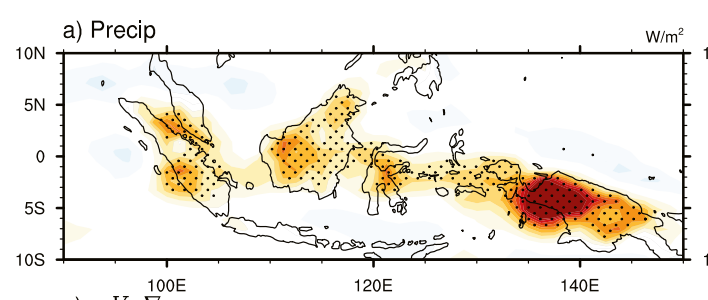

b) Surface Latent Heat Flux
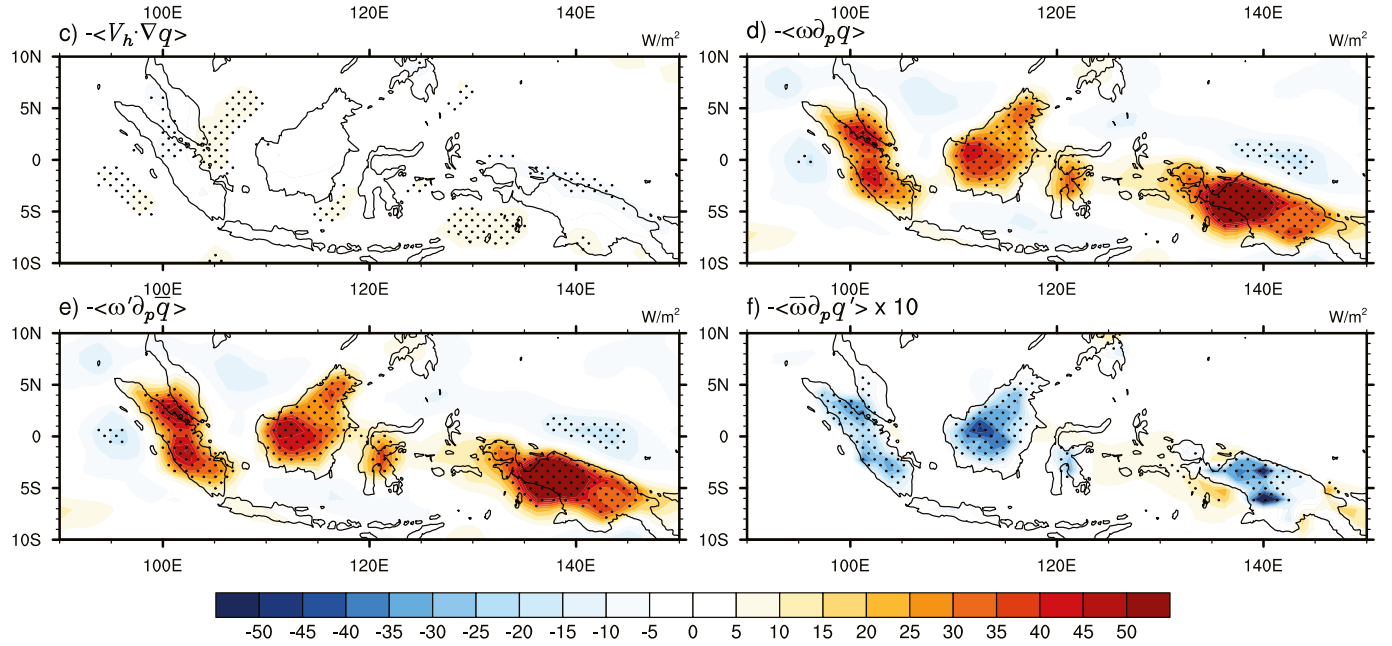

FIG. 5. As in Fig. 3, but for annual mean (a) precipitation, (b) surface latent heat flux, (c) vertically integrated horizontal moisture advection, and (d) vertically integrated vertical moisture advection, and the (e) dynamic component and (f) thermodynamic component of vertically integrated vertical moisture advection. All the units are in $\mathrm{W} \mathrm{m}^{-2}$. Note that all the values in (f) are multiplied by 10 .

Equation (5) indicates that the precipitation response to the MC deforestation is a combined result of the response from the surface evapotranspiration $\left(\mathrm{ET}^{\prime}\right)$, horizontal moisture advection $\left(-\left\langle\mathbf{v} \cdot \nabla q^{\prime}\right\rangle\right)$, and vertical moisture advection $\left[-\langle\omega(\partial q / \partial p)\rangle^{\prime}\right]$. We show in Figs. 5b-d the changes in the three right-hand side terms in Eq. (5) between the control run and the deforestation run. The figure indicates that the horizontal moisture advection (Fig. 5c) changes little after the deforestation, whereas the latent heat flux term (Fig. 5b; same as Fig. 3c but in different color scales), which represents the surface evapotranspiration effect, decreases after the deforestation. Neither term can explain the precipitation increase in the deforestation run (Fig. 5a), which can only be explained by the large increase in the vertical moisture advection term (Fig. 5d with the MC's land average of $25.5 \mathrm{~W} \mathrm{~m}^{-2}$; the difference is significant with $p$ value $<0.05$ ). Our results suggest that the local precipitation response to deforestation in the $\mathrm{MC}$ region is determined not directly by changes in surface evapotranspiration but rather indirectly via the vertical advection of moisture.

Deforestation can affect the vertical moisture advection term by changing the amount of moisture $q$ or the intensity of the vertical velocity $\omega$. To further understand how the deforestation affects the vertical moisture advection, we divide this term into its dynamic $\left(-\omega^{\prime}\langle\partial \bar{q} / \partial p\rangle\right)$ and thermodynamic components $\left[-\left\langle\bar{\omega}\left(\partial q^{\prime} / \partial p\right)\right\rangle\right]$. We find that the MC deforestation affects the vertical advection term primarily through the dynamic component (Fig. 5e) but not the thermodynamic component (Fig. 5f). The considerable increase in the dynamic component of vertically integrated vertical moisture advection $\left(\omega^{\prime} d q\right.$; $27.5 \mathrm{~W} \mathrm{~m}^{-2}$, with $p$ value $\left.<0.05\right)$ compensates for a decrease in the latent heat flux term $\left(-9.60 \mathrm{~W} \mathrm{~m}^{-2}\right.$, with $p$ value $<0.05)$ and is most responsible for the precipitation increase in the deforestation run (cf. Figs. 5a,e). The results reveal that the dynamic component, which is related to the anomalous ascending motion, played a crucial role in the increase in local precipitation.

\section{d. Precipitation response to MC deforestation in RegCM4}

The precipitation changes and the corresponding vertically integrated water budget in the RegCM4 simulations are also examined (Fig. 6) and found to be consistent with the results found in the CESM simulations. The dynamic component of the vertically integrated vertical moisture advection $\left(\left\langle\omega^{\prime} d q\right\rangle 38.9 \mathrm{~W} \mathrm{~m}^{-2}\right.$, with $p$ value $<0.05$; Fig. 6e) also plays a major role in the 
RegCM Climatology Difference (DEF-CTR)
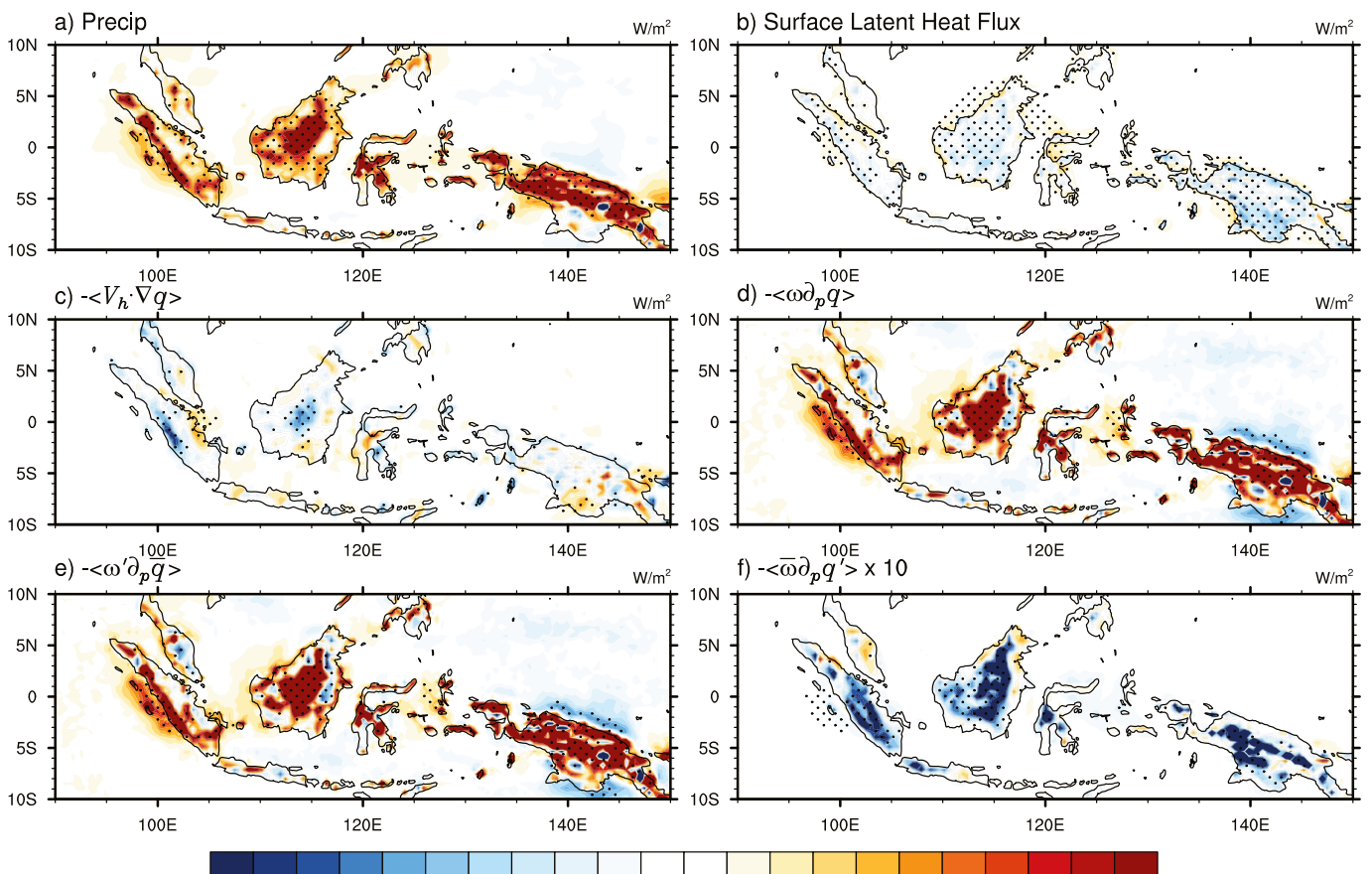

$\begin{array}{lllllllllllllllllllll}-50 & -45 & -40 & -35 & -30 & -25 & -20 & -15 & -10 & -5 & 0 & 5 & 10 & 15 & 20 & 25 & 30 & 35 & 40 & 45 & 50\end{array}$

FIG. 6. As in Fig. 5, but for the results in RegCM4. Note that all the values in (f) are multiplied by 10.

precipitation increase $\left[36.4 \mathrm{~W} \mathrm{~m}^{-2}\right.$ (i.e., $1.30 \mathrm{~mm} \mathrm{day}^{-1}$, with $p$ value $<0.05)]$. The horizontal moisture advection $\left(-\langle\mathbf{v} \cdot \nabla q\rangle^{\prime}\right)$ (Fig. 6c) in the RegCM4 decreases in central Borneo and western Sumatra, which is not found in the CESM (Fig. 5c). Moreover, similar to the local hydroclimate response, the responses to deforestation in the water budget terms (Figs. 5c-f) have a smoother spatial structure in the CESM simulations than in the RegCM4 simulations (Figs. 6c-f).

\section{e. The dynamic effect of the MC deforestation}

To understand the mechanism that induces the precipitation changes, we examine the changes in the vertical profile of the dynamic component of the moisture advection term (i.e., the ascending motion changes weighted by specific humidity) over the land area of the $\mathrm{MC}$ between the control run and the deforestation run (Fig. 7a for CESM and Fig. 7b for RegCM4). The most obvious feature in the figure is that the ascending motion is intensified by the deforestation in both models, which is consistent with the increased precipitation mentioned earlier. The vertical profiles indicate that the largest increase in the ascending motion occurs around $850 \mathrm{hPa}$.

Next the relationships among the vertical moist static stability, convection, and precipitation are further explored in the theoretical framework of Neelin and Held (1987), in which they showed that an increase in the
MSE in the lower to middle troposphere has a tendency to increase the precipitation. In the deforestation simulations, the land surface forcing is prescribed, which leads to higher surface temperatures and provides a thermodynamic source to trigger the instability in the atmosphere. The convection also leads to vertical mixing of the MSE. Thus, we examine the vertical profile of the differences in MSE between the control run and the deforestation run (Fig. 7c for CESM and Fig. 7d for RegCM4). The lapse rate of the MSE difference becomes more negative at approximately $850 \mathrm{hPa}$ in CESM experiments (Fig. 7c) and 950 to $850 \mathrm{hPa}$ as well as above $600 \mathrm{hPa}$ in the RegCM4 experiments (Fig. 7d) in the deforestation simulations than in the control simulations. The more unstable atmosphere is consistent with the vertical profile of anomalous ascending motions shown in Figs. 7a and 7b.

We also examine the changes in the vertical profiles of the three terms of the MSE, namely the sensible, latent, and potential energy in Eq. (7). As shown in Figs. 7c and $7 \mathrm{~d}$, deforestation induces two competing effects in the MSE at low levels (below $850 \mathrm{hPa}$ in the CESM experiments and below $800 \mathrm{hPa}$ in the RegCM4 experiments). These two effects are related to the sensible energy $\left(C_{p} T^{\prime}\right)$ and the latent energy $\left(L q^{\prime}\right)$ components of the MSE. Deforestation reduces the specific humidity near the surface resulting in a positive lapse rate of the 

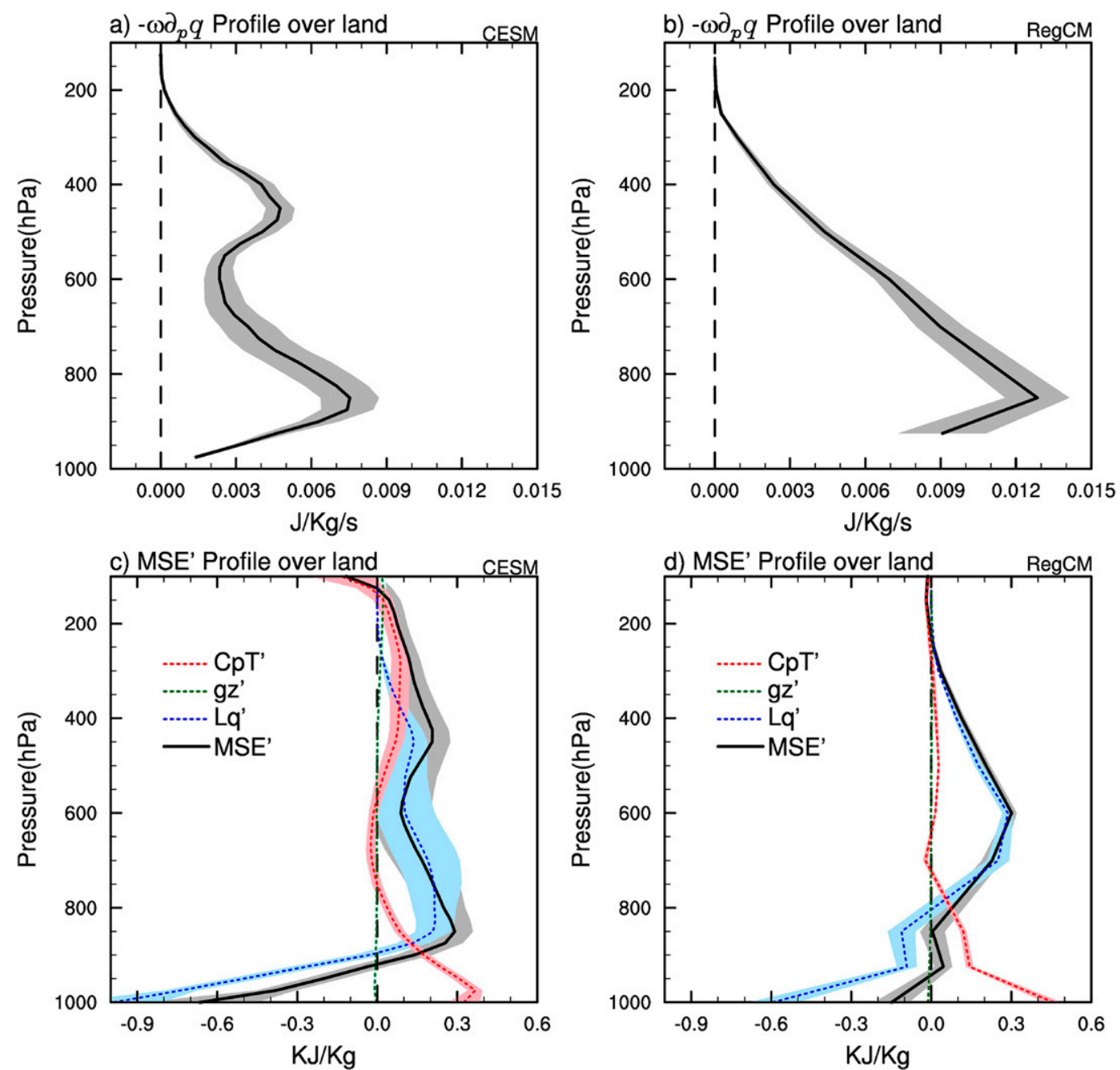

FIG. 7. Profile of difference between deforestation simulation and control simulation (DEF minus CTR) in the dynamic component of vertical moisture advection $\left(\mathrm{J} \mathrm{kg}^{-1} \mathrm{~s}^{-1}\right)$ over land for (a) CESM, and (b) RegCM4, and in MSE ( $\mathrm{kJ} \mathrm{kg}^{-1}$ ) for (c) CESM and (d) RegCM4. The shaded area represents the region within $95 \%$ confidence intervals for annual mean.

latent energy in the lower atmosphere. This latent energy part of the MSE makes the lower atmosphere more stable. The lower atmosphere is less stable in the RegCM4 due to the reduced drying effects near the surface (Fig. 7d) compared to the CESM (Fig. 7c), but such a stable tendency in the RegCM4 is up to $600 \mathrm{hPa}$ (Fig. 7d). At the same time, deforestation warms the surface and induces a negative lapse rate of the sensible energy. This sensible energy component of the MSE tends to make the lower atmosphere more unstable. However, above 800 (700) hPa for the CESM (RegCM4), the sensible energy component of the MSE becomes minor, and the MSE is dominated by the latent energy component, whose lapse rate becomes negative. It is this latent energy component of the MSE that tends to make the atmosphere more unstable and leads to the intensified ascending motion in the deforestation run. The long-term average MSE gradient between 850 and 1000 (600 and $1000) \mathrm{hPa}$ is approximately $0.7(0.5) \mathrm{kJ} \mathrm{kg}^{-1}$ for CESM (RegCM4). Such relatively small gradients indicate strong MSE mixing by convection. Thus, we conclude that convection tends to release the instability generated by deforestation so there is a tendency to have more convection, and therefore precipitation tends to be higher.

The latent energy term, which is the change of specific humidity induced by deforestation multiplied by the latent heat of vaporization, is shown in Figs. $7 \mathrm{c}$ and $7 \mathrm{~d}$. The profile indicates that the deforestation decreases the water vapor amount over the land areas of the $\mathrm{MC}$ in the lower atmosphere (from the surface to $900 \mathrm{hPa}$ ) but increases the water vapor amount above $900 \mathrm{hPa}$. The 
moisture increase above the lower atmosphere is likely a result of the increased low-level moisture convergence induced by deforestation (Fig. 8a for CESM and Fig. 8b for RegCM4). We further look into the vertical cross section (averaged between $10^{\circ} \mathrm{S}$ and $10^{\circ} \mathrm{N}$ ) of water vapor and meridional wind over the $\mathrm{MC}$ region to study how they change from the control run to the deforestation run only in CESM. The result shown in Fig. $8 \mathrm{c}$ confirms that the intensified ascending motion over the MC above $900 \mathrm{hPa}$ is located right over the region where the moisture convergence from the Indian Ocean and the Pacific Ocean is enhanced. Such an anomalous circulation caused by deforestation over the MC may contribute to changes in the large-scale circulation and trigger remote climate impacts.

\section{f. Possible mechanisms for the different precipitation responses among models}

Figure 9 illustrates the key physical processes controlling the changes in precipitation due to deforestation. Potential processes that contribute to a reduction in rainfall are indicated by black arrows while mechanisms leading to an enhancement of precipitation are indicated by green arrows. As shown in Table 2, evapotranspiration and roughness decrease in the deforested region and are accompanied by increases in surface albedo. To strike a balance in the surface energy budget, the deduction in latent heat flux results in the increases in the other components (i.e., sensible heat flux and upward longwave radiation, which is also consistent with higher surface temperature). This repartition in the surface energy budget is also suggested in Takahashi et al. (2017) and Tölle et al. (2017). Our study shows that an increase in the surface sensible heat flux induces low-level heating and destabilization through its impact on the MSE. The moisture convergence and convection triggered by this bring moisture into the deforested region from the surrounding ocean. This moisture convergence further destabilizes the atmosphere and results in an anomalously wet condition in the middle to high levels. The combined effect of increased surface temperatures and low-level moisture convergence further destabilizes the atmosphere, intensifying ascending motions over the MC. Therefore, the low-level moisture supply and strengthened ascending motions constitute a positive feedback and precipitation tends to increase in spite of the reduction in evapotranspiration.

This mechanism is consistent with the results found in the coupled ocean climate model simulations of Schneck and Mosbrugger (2011) and the noncoupled ocean simulations of Delire et al. (2001). Both of the studies show an enhancement in the convergent winds over the adjacent ocean that leads to an increase in latent heat flux and moisture transport and, as a result, precipitation increases in the deforested region. The wet anomaly is accompanied by an increase in cloud cover and reduction in net surface solar radiation, but the effect of cloud cover is rarely discussed in the previous studies. Nevertheless, it is implied in Takahashi et al. (2017) that the impact of cloud cover is not strong enough to lead to a reduction in energy received by the surface. They employed the Weather Research and Forecasting (WRF) Model to explore the change in the diurnal cycle of precipitation. However, Kumagai et al. (2013) argued that there is a higher ratio of recycling from terrestrial evapotranspiration into the precipitation over Borneo and that deforestation can decrease this recycling process, leading to less precipitation.

The competition between the processes controlling the precipitation impacts in Fig. 9 provides a clue for the inconsistency between different studies. One of the components crucial in determining the tendency in precipitation is the change in net radiation. The balance in the energy budget is the factor leading to lowlevel warming and instability. Albedo and cloud cover play a critical role in this balance. Previous studies did not emphasize the impact of cloud cover, but several of them mentioned the importance of surface albedo. In tropical regions, for example, the response to deforestation is manifested mostly through the changes in evapotranspiration, yielding warmer and drier conditions near the surface. If the albedo becomes much higher, the warming effect of the reduced latent heat flux can be compensated for the cooling associated with the reduction in absorbed solar radiation. As a consequence, outgoing longwave radiation and surface temperature may increase slightly, which implies a weaker warming effect compared to that in the absence of albedo changes. For example, the albedo reduction is larger in the experiment of converting forest to bare ground compared to that in the experiment of changing the maximum stomatal conductance (Takahashi et al. 2017). The available radiation energy decreases more in the bare ground experiment leading to smaller surface temperature increases, which in turn lead to a decreased convective available potential energy. In the end, the bare ground experiment with more substantial albedo decrease shows a decrease in precipitation, while the stomatal conductance experiment with no change in albedo shows an increase in precipitation.

Since the decrease in latent heat flux from the canopy is a direct effect of deforestation, an increase in moisture convergence from the surrounding regions is a key component leading to a wet anomaly (the 
a)

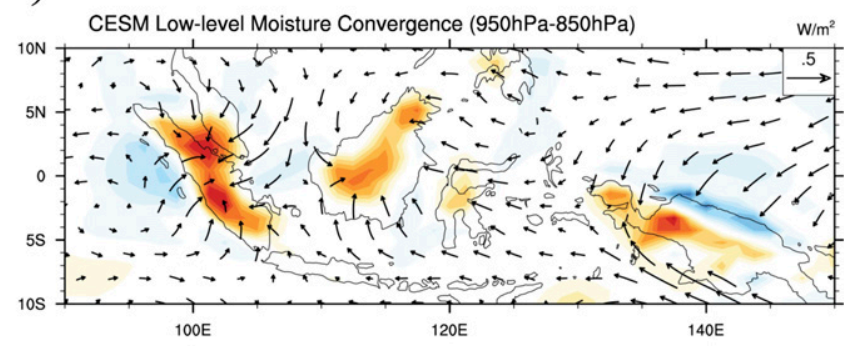

b)

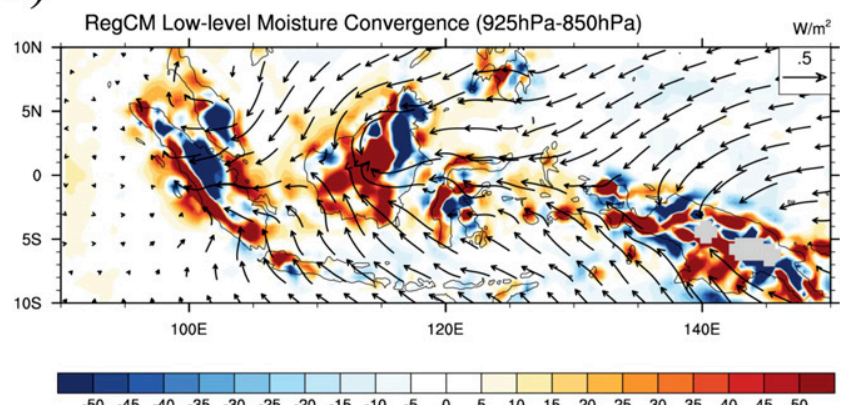

$\begin{array}{llllllllllllllllllllll}-50 & -45 & -40 & -35 & -30 & -25 & -20 & -15 & -10 & -5 & 0 & 5 & 10 & 15 & 20 & 25 & 30 & 35 & 40 & 45 & 50\end{array}$

c)
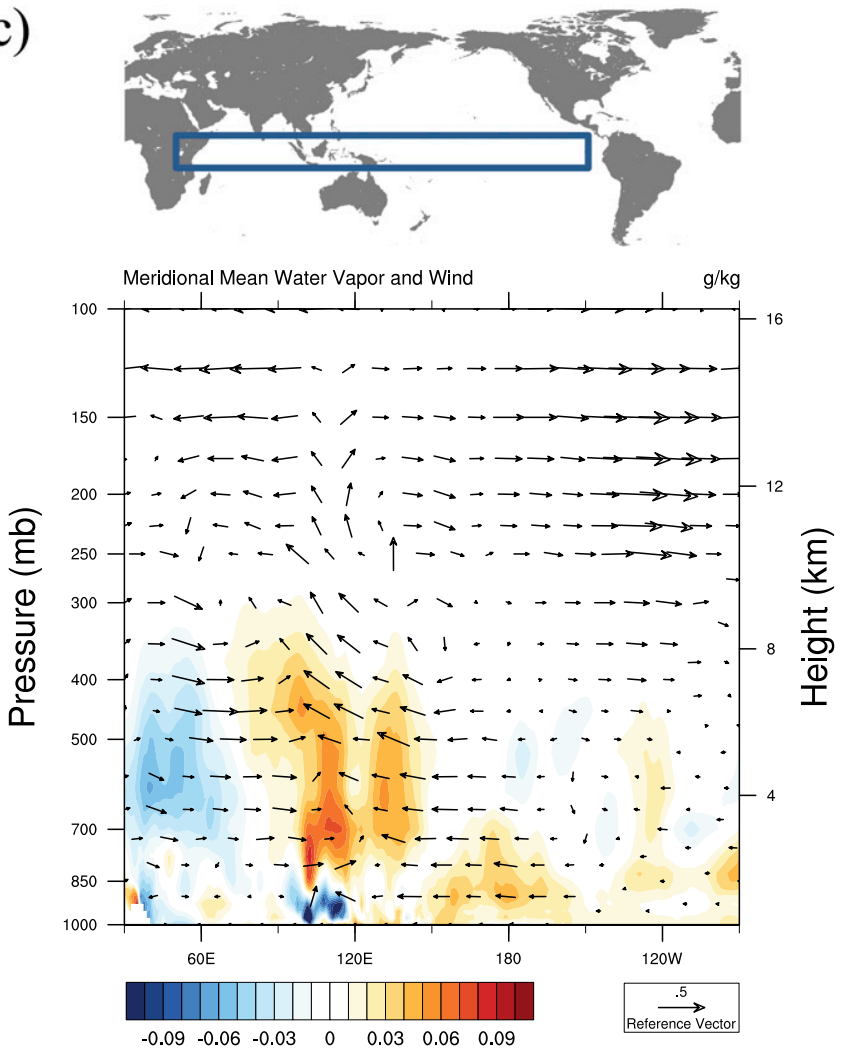

FIG. 8. Annual mean low-level moisture convergence $\left(\mathrm{W} \mathrm{m}^{-2}\right)$ with 950-hPa wind $\left(\mathrm{m} \mathrm{s}^{-1}\right)$ anomalies (DEF minus CTR) for (a) CESM integrated from 950 to $850 \mathrm{hPa}$ and (b) RegCM4 integrated from 925 to $850 \mathrm{hPa}$. (c) Cross section along the equator for CESM annual mean water vapor (shaded; $\mathrm{g} \mathrm{kg}^{-1}$ ) and wind (arrow; $\mathrm{m} \mathrm{s}^{-1}$ ) anomalies (DEF minus CTR) averaged between $10^{\circ} \mathrm{S}$ and $10^{\circ} \mathrm{N}$ (the area of the blue box in the above map). 


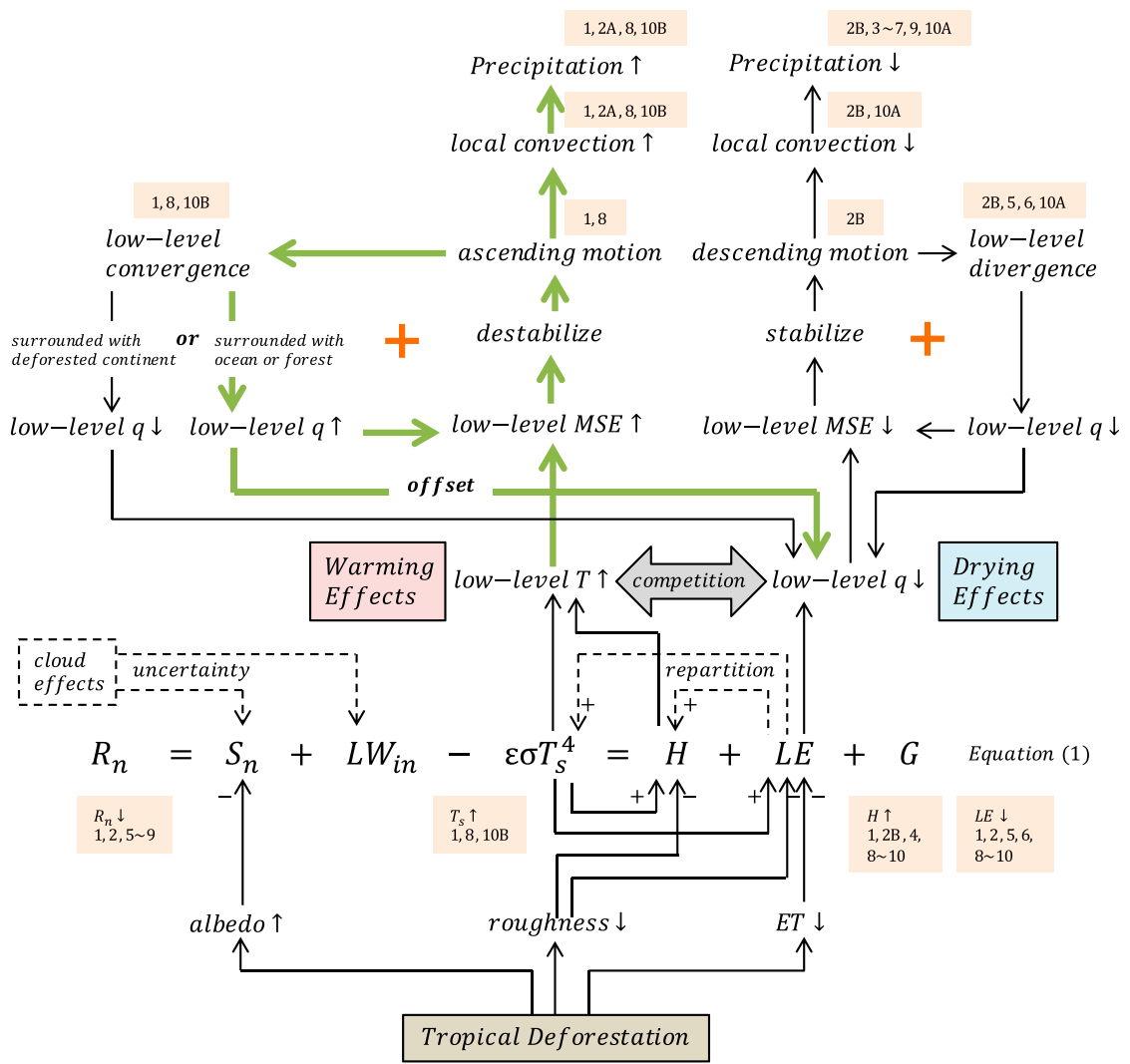

1. Present study (A: CESM, B: RegCM4)

2. Delire et al., 2001 (A: fixed SST, B: coupled)

3. Avissar and Werth, 2005

4. Werth and Avissar, 2005

5. Mabuchi et al., 2005a

6. Mabuchi et al., 2005b

7. Mabuchi et al., 2011
8. Schneck and Mosbrugger, 2011

(precipitation increases in the whole region while decreases in parts of the deforested grids)

9. Tolle et al., 2017

10. Takahashi et al., 2017

(A: change to bare ground,

$B$ : change the maximum stomatal conductance)

FIG. 9. Schematic diagram of how deforestation can influence local precipitation. The detailed description of Eq. (1) is in the methodology. The numbers and references within the orange box correspond to the references in Table 2 . The green arrows indicate the results of the present study.

black arrows in Fig. 9). Two situations, which could contribute to each other, might lead to this condition: either there is not enough convergence to bring in the moisture, or the convergent anomaly exists without moisture provided.

If the local evaporation rate and the influx of moisture from the surrounding deforested area do not increase, the precipitation decreases in the deforested regions (Delire et al. 2001; Werth and Avissar 2005; Takahashi et al. 2017). On the other hand, in the areas with anomalous low-level convergence but without moisture supply, a dry anomaly may be present, resulting in anomalous divergence and weaker convection. Deforestation throughout the Amazonian basin instead of deforestation with "fish-bone" patterns could be one of the examples (Pitman et al. 1993; McGuffie et al. 1995; Sud et al. 1996; Zhang et al. 1996a; Lean and Rowntree 1997) showing whether the environment near deforested areas can provide sufficient moisture from the canopy breezes. Katul et al. (2012) indicated that the rainfall rate increases or decreases depending on whether the vertical motion reaches the lifting condensation level (LCL). Deforestation on small scales is generally accompanied by moist canopy breezes, leading to a lower LCL. Hence, deforestation on small scales could lead to wet anomalies. Large-scale deforestation, on the other hand, which brings dry breezes to the adjacent deforested region, results in a dry anomaly. To summarize, the warming effect of deforestation initially induces low-level convergence. If the deforested area is surrounded by ocean (e.g., the MC) or forest (e.g., deforestation with so-called fish-bone patterns in the Amazon), the moisture supply offsets the 


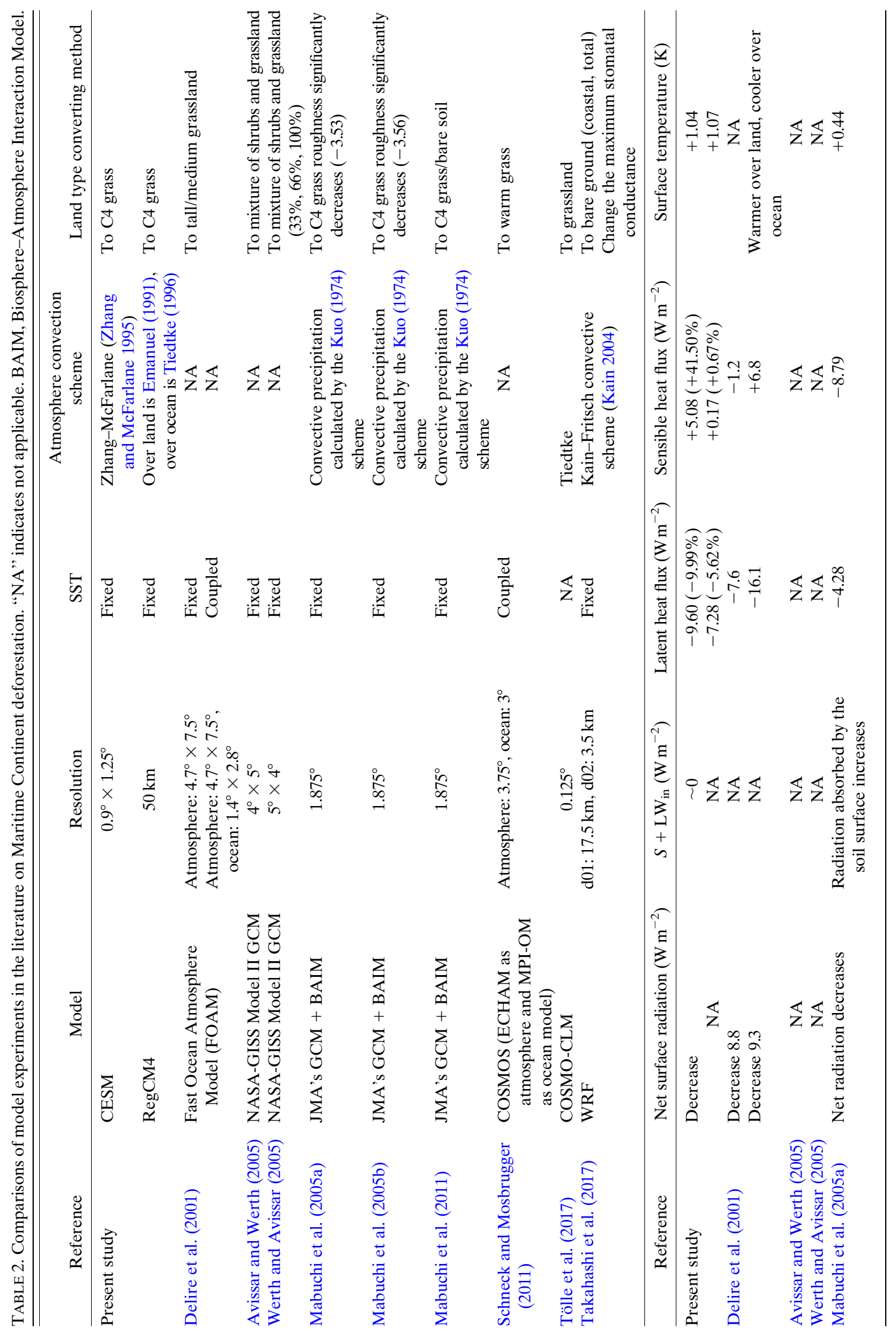




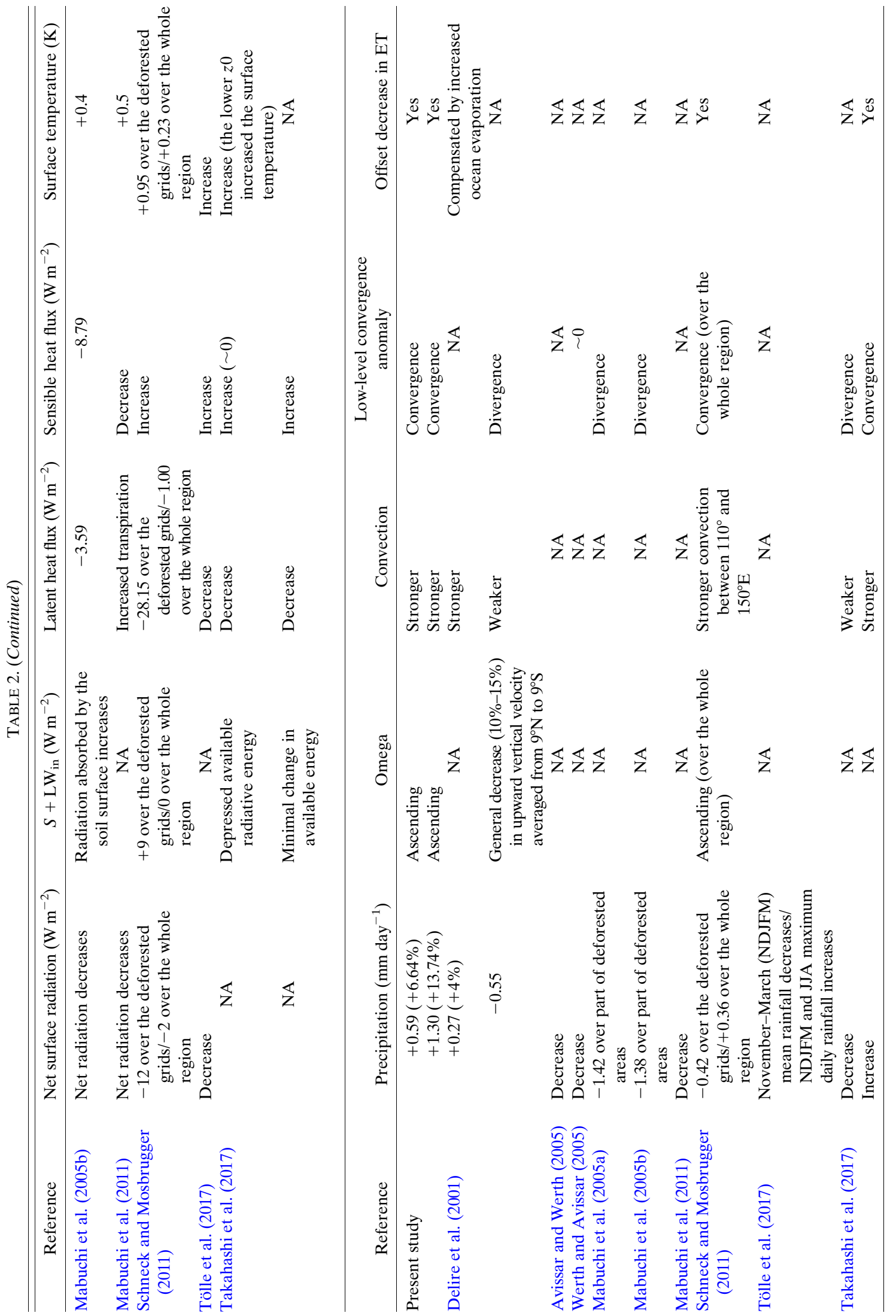


drying effect of deforestation (Schneck and Mosbrugger 2011; Takahashi et al. 2017).

Furthermore, if the roughness is reduced and the aerodynamic exchanges after deforestation are consequently lower, surface sensible and latent heat fluxes are reduced, resulting in an enhanced drying effect. In the studies of Mabuchi et al. (2005a,b), the roughness significantly decreases in the deforestation experiment (vegetation was changed into $\mathrm{C} 4$ grass). Consequently, the surface latent heat flux and sensible heat flux are reduced. The surface latent heat flux decreases by $4.28 \mathrm{~W} \mathrm{~m}^{-2}$ in Mabuchi et al. (2005a) and by $3.59 \mathrm{~W} \mathrm{~m}^{-2}$ in Mabuchi et al. (2005b), which is smaller in magnitude than the decrease in the present study (decreases by $9.60 \mathrm{~W} \mathrm{~m}^{-2}$ in CESM experiments and by $7.28 \mathrm{~W} \mathrm{~m}^{-2}$ in RegCM4 experiments). The surface sensible heat fluxes in Mabuchi et al. (2005a,b) both decrease by $8.79 \mathrm{~W} \mathrm{~m}^{-2}$. As shown in Fig. 9, the reduced latent heat flux enhances the drying effect and the reduced sensible heat flux weakens the warming effect, both of which contribute to a decrease in precipitation. In general, once the drying effect has suppressed the warming effect, precipitation can decrease in response to deforestation (gray double arrow in Fig. 9).

In conclusion, precipitation variations after deforestation are the result of a competition between lowlevel heating and drying. The drying prevents low-level MSE from increasing and suppresses the increase in convection through the processes represented by the black arrows in Fig. 9. The heating might lead to instability in the deforested region and lead to local convergence and convection. Once the moisture convergence compensates for the decrease in water vapor by deforestation, the convection and convergence would lead to a wet anomaly through the mechanisms represented by the green arrows in Fig. 9. Another example supporting this theory is the green-less experiments of Mabuchi et al. (2005a,b). These experiments show a reduction in latent heat flux but an increase in sensible heat flux, resulting in a wet anomaly over the MC.

\section{Discussion}

The results from the CESM deforestation experiments presented here indicate that changes in vertical motion are key factors in determining the precipitation response to MC deforestation. To confirm that this result is not model dependent and is not sensitive to different physical parameterizations among models, such as the specific cumulus schemes, we also performed control and deforestation simulations using a regional climate model, the RegCM4. The RegCM4 experiments produce climate responses to MC deforestation similar to those in the CESM experiments. This result supports the robustness of the climate response to deforestation over the MC region, as there is a consistent pattern in both the regional and global models. Note that CESM uses CLM version 4 (Lawrence et al. 2011) and RegCM4 uses CLM version 4.5 (Oleson et al. 2013), and the major change in CLM4.5 compared to CLM4 is the biogeochemical cycle component of the model. In particular, we note that the local responses in near-surface temperatures (considered the most critical response in this study since it can induce the low-level lateral convergence) to the deforestation are very similar. Specifically the RegCM4 deforestation run produces a reduction in surface latent heat flux of $-7.28 \mathrm{Wm}^{-2}$ (averaged for all land regions in MC) and increases in surface temperature of $1 \mathrm{~K}$ and precipitation of $1.30 \mathrm{~mm} \mathrm{day}^{-1}$, which are in line with the results from CESM: $-9.60 \mathrm{~W} \mathrm{~m}^{-2}, 1 \mathrm{~K}$, and $0.59 \mathrm{~mm} \mathrm{day}^{-1}$ for the surface latent heat flux, surface temperature, and precipitation, respectively. In contrast to the agreement of the sign of changes in precipitation, the spatial distributions with a stronger response and statistical significance are different. The RegCM4 shows very strong enhancement along the high mountainous regions (e.g., western Sumatra Island, central Borneo Island), which are not shown in the CESM responses due to its coarse resolution. However, the RegCM4 experiments still produce climate responses to MC deforestation similar to those in the CESM experiments.

It is interesting to note that the deforestation-induced increase in annual mean upward motions in the MC region is comparable to that associated with La Niña events. It is well known that La Niña events can intensify the Walker circulation, increasing upward motions over the western Pacific including the MC region (e.g., Chang et al. 2004; Qian et al. 2010). We demonstrate the comparable impact of MC deforestation and La Niña (including the 1983/84,1984/85, 1988/89, 1995/96, 1998/99, 1999/2000, 2000/01, and 2007/08 La Niña events) by analyzing changes in the $500-\mathrm{hPa}$ omega in the ERAInterim dataset. We used ONI (the oceanic Niño index, based on the 3-month-running mean of Niño-3.4 SST) as the threshold to identify La Niña events listed above. Figure 10 shows the anomalies in 500-hPa omega from the climatology averaged for all these La Niñas from July of the La Niña developing year to June of the following year. The results show that the annual mean anomaly in $500-\mathrm{hPa}$ omega over the MC is approximately $-0.0032 \mathrm{~Pa} \mathrm{~s}^{-1}$ (average for the whole MC domain, including ocean and land) during the La Niña years. The magnitude of the omega change is about the same order as that produced in the MC deforestation 

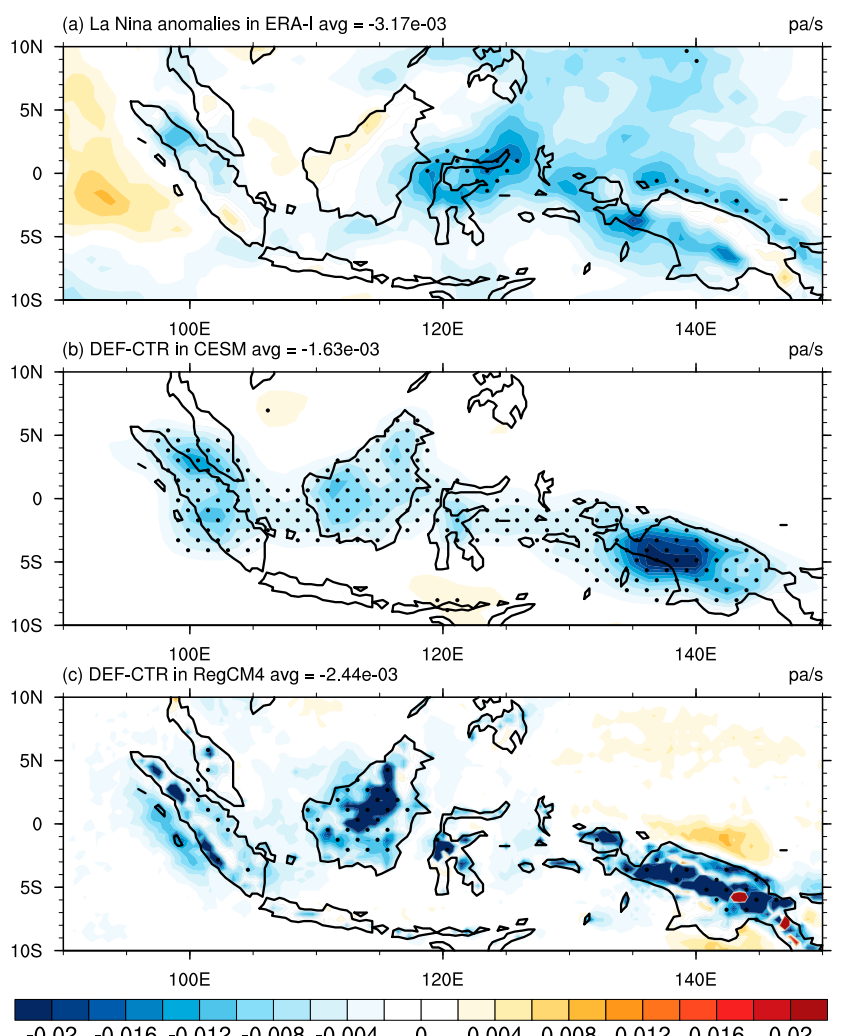

FIG. 10. (a) 500-hPa omega difference between La Niña composite and climatology averaged between July of the developing year and June of the decaying year from ERA-Interim, and 500-hPa omega difference between control and deforestation simulations (DEF minus CTR) for (b) CESM and (c) RegCM4. All the units are in $\mathrm{Pa} \mathrm{s}^{-1}$.

experiments, which is about -0.0016 and $-0.0024 \mathrm{~Pa} \mathrm{~s}^{-1}$ for the CESM and RegCM4, respectively. Therefore, MC deforestation impacts the strength of the Walker circulation to the same degree as La Niña events. This circulation change may enable the MC deforestation to impact the climate in the central-to-eastern Pacific. For example, the trade winds in the central equatorial $\mathrm{Pa}$ cific may be enhanced because of the stronger Walker circulation.

Finally, we review the local responses to the replacement of original rain forest with oil palm plantations. Oil palm plantations usually have lower and less dense canopies than forests. Thus, the surface temperature can increase from $1^{\circ}$ to $6^{\circ} \mathrm{C}$ accompanied by drier conditions (Hardwick et al. 2015; Drescher et al. 2016; Sabajo et al. 2017; Meijide et al. 2018; McAlpine et al. 2018). Replacing forests with $\mathrm{C} 4$ grass as in this study results in similar responses: higher surface temperature and drier conditions. However, Manoli et al. (2018) found that young oil palm trees can decrease evapotranspiration (compared to forests) but older oil palm trees (age $>8$ $9 \mathrm{yr})$ may transpire more than the forests do. Increased surface temperature is also observed in young oil palm plantations in both model and satellite data. However, the annual average surface temperature in mature oil palms is similar to that in the original forests (Y. Fan 2018, personal communication). Therefore, it will be critical to further explore the age-dependent responses in oil palm plantations using the CLM-Palm model (Fan et al. 2015), including more precise PFT phenology and associated water and energy cycles for modeling oil palm in the MC.

\section{Conclusions}

In this study, we used both a global (CESM) and a regional climate model (RegCM4) to study the impacts of deforestation in the MC region. By comparing the experimental runs that replace forest with grassland with control runs, we find that deforestation tends to increase surface temperatures and precipitation over the land regions in the MC. The surface warming effect resulted from decreases in evapotranspiration and roughness that result in more low-level moisture, which can lead to stronger convection and increased 
precipitation. This process can be analyzed via the vertically integrated moisture budget. This analysis revealed that the dynamic component (i.e., convection term) dominates. By analyzing the MSE profile, we find that the combined effect of higher midlevel specific humidities and temperatures rendered the atmosphere in the deforested areas more unstable than in the control run. The induced intensification of ascending motion leads to an increase in precipitation. The accompanying low-level moisture convergence from the surrounding warm oceans further increases specific humidities. Through these positive feedback processes, the MC deforestation results in greater precipitation over the deforested areas. Moreover, the similar results shown in both CESM and RegCM4 simulations enhance our confidence in using the CESM to explore the remote impacts of MC deforestation in future studies.

In this study, we presented a possible climate response to deforestation in the MC and explored several processes that may have resulted in inconsistency in the precipitation responses in previous studies. One of the major factors is the competition between the warming effect and the drying effect after deforestation in the simulations as shown in Fig. 9. The different ways in which deforestation is achieved and/or the differing parameterizations used in the models, such as larger albedo and roughness changes, may strengthen the drying effect and further reduce the precipitation. For deforestation modeling studies in other regions, the differing environments adjacent to the deforested areas (e.g., ocean, forest, or deforested continent) influence the low-level moisture supply and can result in different precipitation responses to deforestation.

The main focus of this study was to explore the interactions between land and atmosphere after deforestation in the MC, so we have not included the ocean responses in the current experiments. However, these responses can alter the local effects in more important ways and warrant further investigation in future work on this topic. Furthermore, an uncertainty in this study is that our deforestation simulations might overestimate the deforestation response in ocean evaporation as it uses prescribed climatological sea surface temperatures and sea ice concentrations. Delire et al. (2001) used the coupled Fast Ocean Atmosphere Model (Jacob 1997) and showed that ocean upwelling induced by deforestation would cool the sea surface and reduce ocean evaporation. In addition, Schneck and Mosbrugger (2011) also suggested weakened upwelling of cold ocean water, leading to an increase in sea surface temperature as a consequence of deforestation. Ma et al. (2013) also demonstrated that a significant change in the hydroclimatological response to afforestation in China when including the ocean feedbacks. Coupled atmosphere-land-ocean model experiments could be used to address this issue in future studies.

Acknowledgments. We thank the three anonymous reviewers for their constructive comments. We benefit greatly from the fruitful discussion with Dr. Yuanchao Fan on the CLM-Palm issues. This study was supported by the grant of MOST 106-2111-M-002-010-MY4 to National Taiwan University. GPCC and PREC/L precipitation data were provided by the NOAA/OAR/ ESRL PSD, Boulder, Colorado, USA, from their website at https://www.esrl.noaa.gov/psd/. The GPCP combined precipitation data were developed and computed by the NASA Goddard Space Flight Center's Mesoscale Atmospheric Processes Laboratory as a contribution to the GEWEX Global Precipitation Climatology Project, and can be downloaded from https://precip.gsfc.nasa.gov/. APHRODITE data are downloaded from https:// climatedataguide.ucar.edu/climate-data/aphrodite-asianprecipitation-highly-resolved-observational-data-integrationtowards. Interpolated OLR data are provided by the NOAA/OAR/ESRL PSD, Boulder, Colorado, from their website at https://www.esrl.noaa.gov/psd/. The surface air temperature climatology used are CRU TS v4.01 data (https://crudata.uea.ac.uk/cru/data/hrg/) and UDel land-only SAT data (https://www.esrl.noaa.gov/ psd/data/gridded/data.UDel_AirT_Precip.html). The European Centre for Medium-Range Weather Forecasts (ECMWF) provided the ERA-Interim data (http://apps.ecmwf.int/datasets/). J.-Y. Yu was supported by NSF Grants AGS-1505145 and AGS1833075 .

\section{REFERENCES}

Austin, K. G., A. Schwantes, Y. Gu, and P. S. Kasibhatla, 2019: What causes deforestation in Indonesia? Environ. Res. Lett., 14, 024007, https://doi.org/10.1088/1748-9326/aaf6db.

Avissar, R., and D. Werth, 2005: Global hydroclimatological teleconnections resulting from tropical deforestation. J. Hydrometeor. 6, 134-145, https://doi.org/10.1175/JHM406.1.

Carlson, K. M., and Coauthors, 2012: Committed carbon emissions, deforestation, and community land conversion from oil palm plantation expansion in West Kalimantan, Indonesia. Proc. Natl. Acad. Sci. USA, 109, 7559-7564, https://doi.org/10.1073/ pnas.1200452109.

Chang, C.-P., Z. Wang, J. Ju, and T. Li, 2004: On the relationship between western Maritime Continent monsoon rainfall and ENSO during northern winter. J. Climate, 17, 665-672, https:// doi.org/10.1175/1520-0442(2004)017<0665:OTRBWM> 2.0.CO;2.

Chen, L., and P. A. Dirmeyer, 2016: Adapting observationally based metrics of biogeophysical feedbacks from land cover/ land use change to climate modeling. Environ. Res. Lett., 11, 034002, https://doi.org/10.1088/1748-9326/11/3/034002. 
Chen, M., P. Xie, J. E. Janowiak, and P. A. Arkin, 2002: Global land precipitation: A 50-yr monthly analysis based on gauge observations. J. Hydrometeor., 3, 249-266, https://doi.org/ 10.1175/1525-7541(2002)003<0249:GLPAYM>2.0.CO;2.

Chou, C., and J. D. Neelin, 2004: Mechanisms of global warming impacts on regional tropical precipitation. J. Climate, 17, 2688-2701, https://doi.org/10.1175/1520-0442(2004)017<2688: MOGWIO $>2.0 . \mathrm{CO} ; 2$.

,-- J.-Y. Tu, and C.-T. Chen, 2006: Regional tropical precipitation change mechanisms in ECHAM4/OPYC3 under global warming. J. Climate, 19, 4207-4223, https://doi.org/ 10.1175/JCLI3858.1.

Chung, J. X., L. Juneng, F. Tangang, and A. F. Jamaluddin, 2018: Performances of BATS and CLM land-surface schemes in RegCM4 in simulating precipitation over CORDEX Southeast Asia domain. Int. J. Climatol., 38, 794-810, https://doi.org/ $10.1002 /$ joc. 5211 .

Davin, E. L., and N. de Noblet-Ducoudré, 2010: Climatic impact of global-scale deforestation: Radiative versus nonradiative processes. J. Climate, 23, 97-112, https://doi.org/10.1175/ 2009JCLI3102.1.

Delire, C., P. Behling, M. T. Coe, J. A. Foley, R. Jacob, J. Kutzbach, Z. Liu, and S. Vavrus, 2001: Simulated response of the atmosphere-ocean system to deforestation in the Indonesian Archipelago. Geophys. Res. Lett., 28, 2081-2084, https://doi.org/10.1029/2000GL011947.

Drescher, J., and Coauthors, 2016: Ecological and socio-economic functions across tropical land use systems after rainforest conversion. Philos. Trans. Roy. Soc. London, 371, 20150275 , https://doi.org/10.1098/rstb.2015.0275.

Emanuel, K. A., 1991: A scheme for representing cumulus convection in large-scale models. J. Atmos. Sci., 48, 2313-2335, https://doi.org/10.1175/1520-0469(1991)048<2313:ASFRCC > 2.0.CO;2.

Fan, Y., O. Roupsard, M. Bernoux, G. Le Maire, O. Panferov, M. M. Kotowska, and A. Knohl, 2015: A sub-canopy structure for simulating oil palm in the Community Land Model (CLMPalm): Phenology, allocation and yield. Geosci. Model Dev., 8 , 3785-3800, https://doi.org/10.5194/gmd-8-3785-2015.

Findell, K. L., T. R. Knutson, and P. C. D. Milly, 2006: Weak simulated extratropical responses to complete tropical deforestation. J. Climate, 19, 2835-2850, https://doi.org/10.1175/JCLI3737.1.

Gaveau, D. L. A., J. Epting, O. Lyne, M. Linkie, I. Kumara, M. Kanninen, and N. Leader-Williams, 2009: Evaluating whether protected areas reduce tropical deforestation in Sumatra. J. Biogeogr., 36, 2165-2175, https://doi.org/10.1111/ j.1365-2699.2009.02147.x.

_ , and Coauthors, 2014: Four decades of forest persistence, clearance and logging on Borneo. PLOS ONE, 9, e101654, https://doi.org/10.1371/journal.pone.0101654.

—, D. Sheil, Husnayaen, M. A. Salim, S. Arjasakusuma, M. Ancrenaz, P. Pacheco, and E. Meijaard, 2016: Rapid conversions and avoided deforestation: Examining four decades of industrial plantation expansion in Borneo. Sci. Rep., 6 , 32 017, https://doi.org/10.1038/srep32017.

Giorgi, F., and Coauthors, 2012: RegCM4: Model description and preliminary tests over multiple CORDEX domains. Climate Res., 52, 7-29, https://doi.org/10.3354/cr01018.

Hanif, M. F., M. R. Mustafa, A. M. Hashim, and K. W. Yusof, 2016: Deforestation alters rainfall: A myth or reality. IOP Conf. Ser. Earth Environ. Sci., 37, 012029, https://doi.org/10.1088/17551315/37/1/012029.
Hansen, M. C. C., and Coauthors, 2013: High-resolution global maps of 21st-century forest cover change. Science, 342, 850853, https://doi.org/10.1126/science.1244693.

Hardwick, S. R., R. Toumi, M. Pfeifer, E. C. Turner, R. Nilus, and R. M. Ewers, 2015: The relationship between leaf area index and microclimate in tropical forest and oil palm plantation: Forest disturbance drives changes in microclimate. Agric. For. Meteor., 201, 187-195, https://doi.org/10.1016/ j.agrformet.2014.11.010.

Harris, I., P. D. Jones, T. J. Osborn, and D. H. Lister, 2014: Updated high-resolution grids of monthly climatic observations-The CRU TS3.10 dataset. Int. J. Climatol., 34, 623-642, https://doi.org/10.1002/joc.3711.

Henderson-Sellers, A., R. E. Dickinson, T. B. Durbidge, P. J. Kennedy, K. McGuffie, and A. J. Pitman, 1993: Tropical deforestation: Modeling local- to regional-scale climate change. J. Geophys. Res., 98, 7289-7315, https://doi.org/10.1029/92JD02830.

Holtslag, A. A. M., E. I. F. de Bruijn, and H.-L. Pan, 1990: A high-resolution air mass transformation model for shortrange weather forecasting. Mon. Wea. Rev., 118, 15611575, https://doi.org/10.1175/1520-0493(1990)118<1561: AHRAMT $>2.0 . \mathrm{CO} ; 2$.

Huffman, G. J., R. F. Adler, M. Morrissey, D. T. Bolvin, S. Curtis, R. Joyce, B. McGavock, and J. Susskind, 2001: Global precipitation at one-degree daily resolution from multi-satellite observations. J. Hydrometeor., 2, 36-50, https://doi.org/ 10.1175/1525-7541(2001)002<0036:GPAODD>2.0.CO;2.

Jacob, R. L., 1997: Low frequency variability in a simulated atmosphere ocean system. Ph.D. dissertation, University of Wisconsin, $170 \mathrm{pp}$.

Kain, J. S., 2004: The Kain-Fritsch convective parameterization: An update. J. Appl. Meteor., 43, 170-181, https://doi.org/ 10.1175/1520-0450(2004)043<0170:TKCPAU>2.0.CO;2.

Katul, G. G., R. Oren, S. Manzoni, C. Higgins, and M. B. Parlange, 2012: Evapotranspiration: A process driving mass transport and energy exchange in the soil-plant-atmosphere-climate system. Rev. Geophys., 50, RG3002, https://doi.org/10.1029/ 2011RG000366.

Kumagai, T., H. Kanamori, and T. Yasunari, 2013: Deforestationinduced reduction in rainfall. Hydrol. Processes, 27, 38113814, https://doi.org/10.1002/hyp.10060.

Kuo, H. L., 1974: Further studies of the parameterization of the influence of cumulus convection on large-scale flow. J. Atmos. Sci., 31, 1232-1240, https://doi.org/10.1175/1520-0469(1974) 031<1232:FSOTPO > 2.0.CO;2.

Laux, P., P. N. Nguyen, J. Cullmann, T. P. Van, and H. Kunstmann, 2017: How many RCM ensemble members provide confidence in the impact of land-use land cover change? Int. J. Climatol., 37, 2080-2100, https://doi.org/10.1002/joc.4836.

Lawrence, D., and K. Vandecar, 2015: Effects of tropical deforestation on climate and agriculture. Nat. Climate Change, $\mathbf{5}$, 27-36, https://doi.org/10.1038/nclimate2430.

Lawrence, D. M., and Coauthors, 2011: Parameterization improvements and functional and structural advances in version 4 of the Community Land Model. J. Adv. Model. Earth Syst., 3, M03001, https://doi.org/10.1029/2011ms00045.

Lean, J., and P. R. Rowntree, 1997: Understanding the sensitivity of a GCM simulation of Amazonian deforestation to the specification of vegetation and soil characteristics. J. Climate, 10, 1216-1235, https://doi.org/10.1175/15200442(1997)010<1216:UTSOAG > 2.0.CO;2.

Lejeune, Q., E. L. Davin, B. P. Guillod, and S. I. Seneviratne, 2015: Influence of Amazonian deforestation on the future evolution 
of regional surface fluxes, circulation, surface temperature and precipitation. Climate Dyn., 44, 2769-2786, https://doi.org/ 10.1007/s00382-014-2203-8.

Liebmann, B., and C. A. Smith, 1996: Description of a complete (interpolated) outgoing longwave radiation dataset. Bull. Amer. Meteor. Soc., 77, 1275-1277.

Ma, D., M. Notaro, Z. Liu, G. Chen, and Y. Liu, 2013: Simulated impacts of afforestation in East China monsoon region as modulated by ocean variability. Climate Dyn., 41, 2439-2450, https://doi.org/10.1007/s00382-012-1592-9.

Mabuchi, K., 2011: A numerical investigation of changes in energy and carbon cycle balances under vegetation transition due to deforestation in the Asian tropical region. J. Meteor. Soc. Japan, 89, 47-65, https://doi.org/10.2151/jmsj.2011-104.

- Y. Sato, and H. Kida, 2005a: Climatic impact of vegetation change in the Asian tropical region. Part I: Case of the Northern Hemisphere summer. J. Climate, 18, 410-428, https://doi.org/10.1175/JCLI-3273.1.

$\longrightarrow,-$, and $\longrightarrow, 2005 \mathrm{~b}$ : Climatic impact of vegetation change in the Asian tropical region. Part II: Case of the Northern Hemisphere winter and impact on the extratropical circulation. J. Climate, 18, 429-446, https://doi.org/10.1175/JCLI-3274.1.

Mahmood, R. and Coauthors, 2014: Land cover changes and their biogeophysical effects on climate. Int. J. Climatol., 34, 929953, https://doi.org/10.1002/joc.3736.

Maloney, B. K., 1998: Human Activities and the Tropical Rainforest: Past, Present and Possible Future. Kluwer Academic, 206 pp.

Malyshev, S., E. Shevliakova, R. J. Stouffer, and S. W. Pacala, 2015: Contrasting local versus regional effects of land-use-changeinduced heterogeneity on historical climate: Analysis with the GFDL Earth System Model. J. Climate, 28, 5448-5469, https:// doi.org/10.1175/JCLI-D-14-00586.1.

Manoli, G., A. Meijide, N. Huth, A. Knohl, Y. Kosugi, P. Burlando, J. Ghazoul, and S. Fatichi, 2018: Ecohydrological changes after tropical forest conversion to oil palm. Environ. Res. Lett., 13, 064035, https://doi.org/10.1088/1748-9326/aac54e.

Margono, B. A., P. V. Potapov, S. Turubanova, F. Stolle, and M. C. Hansen, 2014: Primary forest cover loss in Indonesia over 2000-2012. Nat. Climate Change, 4, 730-735, https://doi.org/ 10.1038/nclimate2277.

McAlpine, C. A., and Coauthors, 2018: Forest loss and Borneo's climate. Environ. Res. Lett., 13, 044009, https://doi.org/ 10.1088/1748-9326/aaa4ff.

McGuffie, K., A. Henderson-Sellers, H. Zhang, T. B. Durbidge, and A. J. Pitman, 1995: Global climate sensitivity to tropical deforestation. Global Planet. Change, 10, 97-128, https:// doi.org/10.1016/0921-8181(94)00022-6.

Meijide, A., C. S. Badu, F. Moyano, N. Tiralla, D. Gunawan, and A. Knohl, 2018: Impact of forest conversion to oil palm and rubber plantations on microclimate and the role of the 2015 ENSO event. Agric. For. Meteor., 252, 208-219, https:// doi.org/10.1016/j.agrformet.2018.01.013.

Neale, R. B., and Coauthors, 2012: Description of the NCAR Community Atmosphere Model (CAM 5.0). NCAR Tech. Note NCAR/TN-486+STR, 274 pp., www.cesm.ucar.edu/ models/cesm1.0/cam/docs/description/cam5_desc.pdf.

Neelin, J. D., and I. M. Held, 1987: Modeling tropical convergence based on the moist static energy budget. Mon. Wea. Rev., 115, 3-12, https://doi.org/10.1175/1520-0493(1987)115<0003: MTCBOT $>2.0 . \mathrm{CO} ; 2$.

Negri, A. J., R. F. Adler, L. Xu, and J. Surratt, 2004: The impact of Amazonian deforestation on dry-season rainfall.
J. Climate, 17, 1306-1319, https://doi.org/10.1175/15200442(2004)017<1306:TIOADO > 2.0.CO;2.

Oleson, K. W., and Coauthors, 2010: Technical description of version 4.0 of the Community Land Model (CLM). NCAR Tech. Note NCAR/TN-478+STR, 257 pp., https://doi.org/ 10.5065/D6FB50WZ.

—_, and Coauthors, 2013: Technical description of version 4.5 of the Community Land Model (CLM). NCAR Tech. Note NCAR/TN-503+STR, 420 pp., https://doi.org/10.5065/ D6RR1W7M.

Pielke, R. A., J. Adegoke, A. Beltraán-Przekurat, C. A. Hiemstra, J. Lin, U. S. Nair, D. Niyogi, and T. E. Nobis, 2007: An overview of regional land-use and land-cover impacts on rainfall. Tellus, 59B, 587-601, https://doi.org/10.1111/j.1600-0889.2007.00251.x.

Pitman, A. J., T. B. Durbidge, A. Henderson-Sellers, and K. McGuffie, 1993: Assessing climate model sensitivity to prescribed deforested landscapes. Int. J. Climatol., 13, 879898, https://doi.org/10.1002/joc.3370130806.

Polcher, J., and K. Laval, 1994: The impact of African and Amazonian deforestation on tropical climate. J. Hydrol., 155, 389-405, https://doi.org/10.1016/0022-1694(94)90179-1.

Qian, J.-H., A. W. Robertson, and V. Moron, 2010: Interactions among ENSO, the monsoon, and diurnal cycle in rainfall variability over Java, Indonesia. J. Atmos. Sci., 67, 3509-3524, https://doi.org/10.1175/2010JAS3348.1.

Radersma, S., and N. de Ridder, 1996: Computed evapotranspiration of annual and perennial crops at different temporal and spatial scales using published parameter values. Agric. Water Manage., 31, 17-34, https://doi.org/10.1016/03783774(95)01235-4.

Ramos da Silva, R., D. Werth, and R. Avissar, 2008: Regional impacts of future land-cover changes on the Amazon basin wet-season climate. J. Climate, 21, 1153-1170, https://doi.org/ 10.1175/2007JCLI1304.1.

Roy, S. B., 2009: Mesoscale vegetation-atmosphere feedbacks in Amazonia. J. Geophys. Res., 114, D20111, https://doi.org/ 10.1029/2009JD012001.

Sabajo, C. R., G. le Maire, T. June, A. Meijide, O. Roupsard, and A. Knohl, 2017: Expansion of oil palm and other cash crops causes an increase of the land surface temperature in the Jambi province in Indonesia. Biogeosciences, 14, 4619-4635, https://doi.org/10.5194/bg-14-4619-2017.

Sage, R. F., D. A. Wedin, and M. Li, 1999: The biogeography of C4 photosynthesis: Patterns and controlling factors. C4 Plant Biology, R. F. Sage and R. K. Monson, Eds., Academic Press, 313-373.

Schneck, R., and V. Mosbrugger, 2011: Simulated climate effects of Southeast Asian deforestation: Regional processes and teleconnection mechanisms. J. Geophys. Res., 116, D11116, https://doi.org/10.1029/2010JD015450.

Schneider, U., A. Becker, P. Finger, A. Meyer-Christoffer, B. Rudolf, and M. Ziese, 2011: GPCC full data reanalysis version 6.0 at $0.5^{\circ}$ : Monthly land-surface precipitation from rain-gauges built on GTS-based and historic data. GPCC, accessed October 2013, https:/doi.org/10.5676/DWD_GPCC/FD_ M_V6_050.

Snyder, P. K., 2010: The influence of tropical deforestation on the Northern Hemisphere climate by atmospheric teleconnections. Earth Interact., 14, 1-34, https://doi.org/10.1175/ 2010EI280.1.

Snyman, H. A., W. L. J. van Rensburg, and W. D. Venter, 1997: Transpiration and water-use efficiency in response to water stress in Themeda triandra and Eragrostis lehmanniana. S. Afr. J. Bot., 63, 55-59, https://doi.org/10.1016/S0254-6299(15)30693-1. 
Spracklen, D. V., and L. Garcia-Carreras, 2015: The impact of Amazonian deforestation on Amazon basin rainfall. Geophys. Res. Lett., 42, 9546-9552, https://doi.org/ 10.1002/2015GL066063

Sud, Y. C., W. K.-M. Lau, G. K. Walker, J.-H. Kim, G. E. Liston, and P. J. Sellers, 1996: Biogeophysical consequences of a tropical deforestation scenario: A GCM simulation study. J. Climate, 9, 3225-3247, https://doi.org/10.1175/15200442(1996)009<3225:BCOATD>2.0.CO;2.

Takahashi, A., T. Kumagai, H. Kanamori, H. Fujinami, T. Hiyama, and M. Hara, 2017: Impact of tropical deforestation and forest degradation on precipitation over Borneo island. J. Hydrometeor., 18, 2907-2922, https://doi.org/10.1175/ JHM-D-17-0008.1.

Tan, P.-H., C. Chou, and J.-Y. Tu, 2008: Mechanisms of global warming impacts on robustness of tropical precipitation asymmetry. J. Climate, 21, 5585-5602, https://doi.org/10.1175/ 2008JCLI2154.1.

Tiedtke, M., 1996: An extension of cloud-radiation parameterization in the ECMWF model: The representation of subgrid-scale variations of optical depth. Mon. Wea. Rev., 124 745-750, https://doi.org/10.1175/1520-0493(1996)124<0745: AEOCRP $>2.0 . \mathrm{CO} ; 2$.

Tölle, M. H., S. Engler, and H.-J. Panitz, 2017: Impact of abrupt land cover changes by tropical deforestation on Southeast Asian climate and agriculture. J. Climate, 30, 2587-2600, https://doi.org/10.1175/JCLI-D-16-0131.1.

van der Molen, M. K., A. J. Dolman, M. J. Waterloo, and L. A Bruijnzeel, 2006: Climate is affected more by maritime than by continental land use change: A multiple scale analysis. Global Planet. Change, 54, 128-149, https://doi.org/10.1016/ j.gloplacha.2006.05.005.

Voldoire, A., and J. F. Royer, 2004: Tropical deforestation and climate variability. Climate Dyn., 22, 857-874, https://doi.org/ 10.1007/s00382-004-0423-z.

Wang, J., and Coauthors, 2009: Impact of deforestation in the Amazon basin on cloud climatology. Proc. Natl. Acad. Sci. USA, 106, 3670-3674, https://doi.org/10.1073/pnas. 0810156106

Wang, L., and K. K. W. Cheung, 2017: Potential impact of reforestation programmes and uncertainties in land cover effects over the loess plateau: A regional climate modeling study.
Climatic Change, 144, 475-490, https://doi.org/10.1007/s10584016-1848-1.

Werth, D., and R. Avissar, 2005: The local and global effects of Southeast Asian deforestation. Geophys. Res. Lett., 32, L20702, https://doi.org/10.1029/2005GL022970.

Willmott, C. J., and K. Matsuura, 2001: Terrestrial air temperature and precipitation: Monthly and annual time series (1950-1999). Accessed October 2018, ftp://ftp.cdc.noaa.gov/ Datasets/udel.airt.precip/air.mon.mean.v401.nc.

Yatagai, A., K. Kamiguchi, O. Arakawa, A. Hamada, N. Yasutomi, and A. Kitoh, 2012: APHRODITE: Constructing a longterm daily gridded precipitation dataset for Asia based on a dense network of rain gauges. Bull. Amer. Meteor. Soc., 93, 1401-1415, https://doi.org/10.1175/BAMS-D11-00122.1.

Zeng, N., and J. D. Neelin, 1999: A land-atmosphere interaction theory for the tropical deforestation problem. J. Climate, 12, 857-872, https://doi.org/10.1175/1520-0442(1999)012<0857: ALAITF $>2.0 . \mathrm{CO} ; 2$

Zeng, X., M. Zhao, and R. E. Dickinson, 1998: Comparison of bulk aerodynamic algorithms for the computation of sea surface fluxes using the TOGA COARE data. J. Climate, 11, 2628-2644, https://doi.org/10.1175/1520-0442(1998)011<2628: IOBAAF $>2.0 . \mathrm{CO} ; 2$.

Zhang, G. J., and N. A. McFarlane, 1995: Sensitivity of climate simulations to the parameterization of cumulus convection in the Canadian Climate Centre general circulation model. Atmos.-Ocean, 33, 407-446, https://doi.org/10.1080/ 07055900.1995 .9649539$.

Zhang, H., A. Henderson-Sellers, and K. McGuffie, 1996a: Impacts of tropical deforestation. Part I: Process analysis of local climatic change. J. Climate, 9,1497-1517, https://doi.org/10.1175/ 1520-0442(1996)009<1497:IOTDPI > 2.0.CO;2.

,$- \ldots$, and $-1996 \mathrm{~b}$ : Impacts of tropical deforestation. Part II: The role of large-scale dynamics. J. Climate, 9, 2498-2521, https://doi.org/10.1175/1520-0442(1996)009<2498:IOTDPI > 2.0.CO;2

Zhang, X., Z. Xiong, X. Zhang, Y. Shi, J. Liu, Q. Shao, and X. Yan, 2016: Using multi-model ensembles to improve the simulated effects of land use/cover change on temperature: A case study over northeast China. Climate Dyn., 46, 765-778, https:// doi.org/10.1007/s00382-015-2611-4. 